\title{
Cu(II)-metalated Silica-based Inorganic-Organic Hybrid: Synthesis, Characterization and Its Evaluation for Dye Degradation and Oxidation of Organic Substrates
}

\author{
A. Naz, ${ }^{a}$ S. Arun, ${ }^{b}$ R. Kumari, ${ }^{a}$ S. S. Narvi, ${ }^{a}$ and M. S. Alam ${ }^{c, *}$ \\ aDepartment of Chemistry, Motilal Nehru National Institute of \\ Technology Allahabad, Prayagraj, Uttar Pradesh, India-211004 \\ bDepartment of Chemistry, Dr. Shakuntala Misra \\ National Rehabilitation University, Lucknow, \\ Uttar Pradesh, India-226017 \\ 'Department of Chemical Engineering, \\ Motilal Nehru National Institute of Technology Allahabad, \\ Prayagraj, Uttar Pradesh, India-211004
}

doi: https://doi.org/10.15255/CABEQ.2020.1906

Original scientific paper

Received: December 23, 2020

Accepted: September 6, 2021

\begin{abstract}
A novel and efficacious inorganic-organic hybrid material was synthesized by immobilizing $\mathrm{Cu}$ (II)-Schiff's base complex on silica-gel using 3-(2-aminoethylamino) propyltrimethoxysilane as linker and 1,3-diphenyl-1,3-propanedione for Schiff's base formation. The hybrid was characterized by FT-IR, DRUV-Vis, Solid State ${ }^{13} \mathrm{C}$ CPMAS NMR, Powder-XRD, SEM, ICP-AES, EDX and TGA and EPR techniques. Catalytic ability of the hybrid was evaluated for oxidative degradation of Reactive Black 5, and oxidation of few representative organic substrates, viz., tetralin, cyclohexane, cyclohexanol, and cyclopentanol, where the hybrid catalyst decomposes $\mathrm{H}_{2} \mathrm{O}_{2}$ to generate $\cdot \mathrm{OH}$ free radicals. Influence of various reaction parameters, i.e., $\mathrm{H}_{2} \mathrm{O}_{2}$ concentration, catalyst concentration, and temperature, on dye degradation process was studied and best reaction conditions for maximum degradation of RB5 were also determined. The catalyst gave a high dye degradation efficiency of $91 \%$, and a good product yield of $42.61 \%, 41.09 \%$, $40.54 \%$, and $38.44 \%$ for conversion of tetralin (with selectivity of $74.23 \%$ and $25.77 \%$ for tetralone and tetralol, respectively), cyclohexane (with selectivity of $75.05 \%$ and $24.95 \%$ for cyclohexanone and cyclohexanol, respectively), cyclohexanol (with $100 \%$ selectivity for cyclohexanone), and cyclopentanol (with $100 \%$ selectivity for cyclopentanone), respectively. Easy separation, reusability, and good catalytic activity leading to possible development of eco-friendly industrial manufacturing process are the motivating factors for using the synthesized novel material.
\end{abstract}

Keywords:

inorganic-organic hybrid, silica gel, catalysis, Reactive Black 5, hydrogen peroxide

\section{Introduction}

Rapidly increasing environmental pollution, formation of hazardous substances, and a number of health related challenges in everyday life compels us to move towards green chemistry, and to synthesize such materials and equipment that could enhance the general well-being of individuals and the society. Development of inorganic-organic hybrid materials is one such approach. The combination of organic and inorganic species results in a material having synergistic effect of both the components. These materials have proved to be effective in many areas, such as barrier coatings, sensors, solar cells, catalysts, and medical applications ${ }^{1-5}$ The use of

"Corresponding author: Tel.: +91-532 2271584,

E-mail address: msalam@mnnit.ac.in such hybrids as heterogeneous catalysts has been of great interest for researchers in the last decade. The hybrids may be synthesized by simple strategies. One strategy of these methods could be immobilizing organic moieties onto silica surface, an inorganic species. Silica gel serves as a good inorganic support owing to; (i) presence of adequate number of silanol groups to which desired organic molecules can be grafted, which can further be modified, (ii) high thermal resistance, (iii) grafted groups are covalently linked and therefore, resistant towards their detachment from the surface of silica through organic solvents or water, and (iv) organically modified $\mathrm{SiO}_{2}$ gel usually facilitates and boosts the adsorption/coordinate bond formation of metal ions ${ }^{6}$, thereby increasing their life span on silica surface ${ }^{7}$. Considering these, inorganic-organic hybrids may 
have good catalytic activity, which can be utilized in environmental remediation, such as waste/effluent treatment, along with enhancement in production capacity of various industrial processes.

In the present work, we have synthesized and characterized a novel silica based $\mathrm{Cu}(\mathrm{II})$ inorganic-organic hybrid compound, obtained by grafting Schiff's base onto silica surface and complexation of the base by $\mathrm{Cu}(\mathrm{II})$ chloride. The metal complex hybrid thus formed was successfully used as a heterogeneous catalyst for oxidative degradation of a non-biodegradable disazo dye, Reactive Black 5 (RB5), as well as in the oxidation of cycloalkanes (i.e., tetralin and cyclohexane) and cycloalcohols (i.e., cyclohexanol and cyclopentanol) by using in both cases hydrogen peroxide as an environmentally amiable green oxidant. To the best of our understanding, this may be regarded as a step towards a reusable inorganic-organic hybrid catalyst for solving the issues of environment as well as of chemical industries simultaneously.

These inorganic-organic hybrids may have found a valuable application as catalysts in the dye degradation ${ }^{8,9}$. Dyes being used in large amounts have adverse effect on biota due to their carcinogenic and toxic behavior, and thus their degradation is a challenge for healthy life. More than $50 \%$ of all produced dyes are azo dyes ${ }^{10}$ and among the azo dyes most widely used are azo reactive dyes having one or several azo $(-\mathrm{N}=\mathrm{N}-)$ groups with substituted aromatic structures ${ }^{11}$. These reactive dyes are widely used in paper, ceramic, textile, pharmaceutical, and food processing industries. The effluents from these industries contain residual dyes, which need proper treatment before being finally released into the environment. Thus, synthesis of novel hybrid recyclable catalyst for treatment of such dyes has become a challenge in recent years. Various methodologies, such as adsorption ${ }^{12}$, filtration pro$\operatorname{cess}^{13,14}$, electrochemical method ${ }^{15}$, coagulation ${ }^{16}$, advanced oxidation processes (AOPs) ${ }^{17,18}$, etc., are being employed for the removal and degradation of dyes. However, the hazardous pollutants from dye wastewater can only be transferred from one phase to another by these techniques, and it is difficult to degrade them through biological treatment process$\mathrm{es}^{19}$. Thus, the final environmental problems remain unresolved by these techniques and, therefore, processes leading to complete mineralization of dyes or their degradation to less harmful compounds are recommended to solve the problem. AOPs using homogeneous catalysts have emerged as a useful method for destruction of such toxic pollutants, where using highly reactive $\cdot \mathrm{OH}$ radicals for driving oxidation process is the characteristic feature of all $\mathrm{AOPs}^{20}$. However, certain problems are associated with homogeneous catalysts, such as difficulty in their separation from reaction mixture. This has forced research groups to move towards insoluble catalysts. Novel hybrid recyclable heterogeneous catalysts can lead to a better approach towards environmental remediation in treating toxic dyes, and therefore, their synthesis has become a challenge in recent years.

The heterogeneous catalysts have also proved to be more viable for oxidation of various alkyl aromatic compounds, cycloalkanes, cycloalkenes, cycloalcohols, sulphides, olefins, etc., ${ }^{21,22}$ in certain industrial processes. Selective conversion of cyclohexane to cyclohexanone and cyclohexanol is an important requirement in chemical industry for the synthesis of Nylon-6,6 and Nylon-6 polymers, where $\varepsilon$-Caprolactam, an essential precursor of $\mathrm{Ny}$ lon- 6 and plastics, can be directly synthesized from cyclohexanol $^{23}$. Cyclopentanone, oxidative product of cyclopentane, is used to synthesize pyridine, pyran, and thiophene derivatives, which exhibit cytotoxicity against some cancer cell lines ${ }^{24}$. Tetralone, a keto derivative of 1,2,3,4-tetrahydro-naphthalene (tetralin), is an important reactive intermediate for materials such as dyes, agrochemicals, and pharmaceuticals ${ }^{25}$. Immobilization of metal complex catalyst over inorganic support is a new strategy, and has the advantage of being selective and efficient as the common advantages of most metal complex catalysts. In continuation of our earlier paper ${ }^{26}$, where we had reported the $\mathrm{Cu}$ (II) containing Schiff's base functionalized inorganic-organic hybrid and its potential application as anti-bacterial agent and as catalyst for dye degradation, we are reporting a new hybrid as catalyst for dye degradation and organic transformation.

\section{Materials and methods}

\section{Materials and characterization techniques}

Silica gel (Sigma Aldrich, India, Davisil Grade 923) with particle size of 100-200 mesh and pore diameter of $30 \AA$ (surface area $=430-530 \mathrm{~m}^{2} \mathrm{~g}^{-1}$ ) was used. 1,3-diphenyl-1,3-propanedione (DPPD, $98 \%$ purity), anhydrous $\mathrm{CuCl}_{2}(\geq 99.995 \%$ trace metals basis; anhydrous grade) and Reactive Black 5 (RB5, Dye content $\geq 50 \%$ ) dye, 3-(2-aminoethylamino) propyltrimethoxysilane (AAPTS, Technical grade, $\geq 80 \%$ ) were purchased from Sigma Aldrich, India. Hydrogen peroxide $(30 \% \mathrm{w} / \mathrm{v}$, analytical reagent), toluene ( $99.5 \%$, analytical reagent), glacial acetic acid, dimethyl sulfoxide, dimethylformamide, and acetonitrile were procured from $\mathrm{CDH}$ (Central Drug House (P) Ltd., India). The concentration of hydrogen peroxide (w/v $30 \%$ ) was verified through iodometric titration; $\mathrm{H}_{2} \mathrm{O}_{2}$ solution was then used for the reaction. Substrates used for oxidation reac- 
tion, i.e., tetralin (98.0 \%, Laboratory Reagent), cyclohexane (99.5\%, Analytical Reagent), cyclohexanol (99.0 \% Analytical Reagent), cyclopentanol (99.0 \%, Synthesis grade) were also purchased from $\mathrm{CDH}$, India. Ethanol ( $\geq 99.9 \%)$ was bought from Merck. All the chemicals were used without purification, except toluene, which was firstly made pure and then used.

Perkin Elmer spectrophotometer (Spectrum Two) was used to obtain FT-IR spectra in the range of $4000-400 \mathrm{~cm}^{-1}$, using $\mathrm{KBr}$ disks. ${ }^{13} \mathrm{C}$ NMR spectral studies were performed at $100.52 \mathrm{MHz}$ by ECX-Jeol 400(S), AVIII400(L) NMR spectrometer. SEM and EDX analyses were performed by CARL ZEISS EVO 50 coupled with Silicon Drift EDS detector fitted with a backscattered electron detector. The samples were coated with thin gold layer before performing SEM analysis. Diffuse reflectance UV-visible spectra were obtained by Shimadzu UV3600 Plus UV-VIS-NIR spectrophotometer, using $\mathrm{BaSO}_{4}$ as reference. Dye concentration was also measured on the same UV-Vis instrument, with optical path length of $1 \mathrm{~cm}$. Milli-Q water was taken as reference for these analyses. The content of copper in the hybrid was analyzed through SPECTRO Analytical Instruments GmbH-ARCOS, Simultaneous ICP Spectrometer. Room temperature EPR analysis was performed through ES-DVT4 Spectrometer at $9.167 \mathrm{GHz}$, using DPPH as standard (g $=2.0036$ ). Thermogravimetric analysis was performed under a dynamic $\mathrm{N}_{2}$ atmosphere in the range of $30{ }^{\circ} \mathrm{C}-800{ }^{\circ} \mathrm{C}$ at a heating rate of $10^{\circ} \mathrm{C} \mathrm{min}-1$ on a Perkin Elmer STA6000 system. Powder-XRD patterns were recorded on Rigaku SmartLab X-ray diffractometer at $25^{\circ} \mathrm{C}$, using step time of $1.0000 \mathrm{sec}$ ond, step size $\left[{ }^{\circ} 2 \theta\right]$ of $0.0200^{\circ}$ and $2 \theta$ with a scan angle from $5^{\circ}$ to $80^{\circ}$. The products obtained after substrates oxidation were analyzed by GC-Mass spectrometry (GC-MS) using Thermo Scientific TSQ 8000 gas chromatograph-mass spectrometer.

\section{Hybrid synthesis}

The hybrid was synthesized as follows:

Silica gel activation $\left(\mathrm{SiO}_{2}\right)$

Silica gel was activated according to the literature ${ }^{27}$. Typically, an excess amount $(50 \mathrm{~mL})$ of $1: 1$ (conc. $\mathrm{HCl}): \mathrm{H}_{2} \mathrm{O}(\mathrm{v}: \mathrm{v})$ was added to silica gel $(6 \mathrm{~g})$ and refluxed for $6 \mathrm{~h}$ at $105^{\circ} \mathrm{C}\left( \pm 1{ }^{\circ} \mathrm{C}\right)$. The suspension was filtered and the solid was washed with Milli-Q water until $\mathrm{pH} 7$ was attained, the $\mathrm{pH}$ was monitored by $\mathrm{pH}$ meter. Silica gel was finally dried at $120{ }^{\circ} \mathrm{C}\left( \pm 1{ }^{\circ} \mathrm{C}\right)$ for $12 \mathrm{~h}$ in hot air oven. The activation of silica gel was verified by FTIR analysis which showed surface silanol stretching vibrations at $3442 \mathrm{~cm}^{-1}$ and surface silanol bending vibrations ${ }^{27}$ at $1639 \mathrm{~cm}^{-1}$ (Fig. 1a)
Synthesis of amino-functionalized silica gel $\left(\mathrm{SiO}_{2}{ }^{*} \mathrm{NH}_{2}\right)$

The immobilization of 3-(2-aminoethylamino) propyltrimethoxysilane (AAPTS) on silica gel was achieved by slightly altering the method as reported by Antony et al. ${ }^{7}$ The activated silica gel $(5 \mathrm{~g})$ and solution of AAPTS $(23.12 \mathrm{mmol})$ in anhydrous toluene $(25 \mathrm{~mL})$ were mixed and the suspension was refluxed for $24 \mathrm{~h}$ at $115 \pm 1^{\circ} \mathrm{X}$ under $\mathrm{N}_{2}$ atmosphere and filtered. The solid was washed with toluene, ethanol, and diethyl ether. Soxhlet extraction was performed with a 1:1 solution of ethanol and dichloromethane (DCM) to remove any silylating reagent residue adsorbed on silica surface. It was then dried at $50{ }^{\circ} \mathrm{C}\left( \pm 1{ }^{\circ} \mathrm{C}\right)$ under vacuum. FTIR was recorded to confirm the grafting of organic moiety, which showed $\mathrm{C}-\mathrm{H}$ stretching vibrations at 2901 $\mathrm{cm}^{-1}, \mathrm{C}-\mathrm{H}$ bending vibrations at $1490 \mathrm{~cm}^{-1}$ and $\mathrm{NH}_{2}$ bending vibrations ${ }^{27,28}$ at $1551 \mathrm{~cm}^{-1}$ (Fig. 1b)

Modification of amino-functionalized silica gel with $\operatorname{DPPD}\left(\mathrm{SiO}_{2}{ }^{*} \mathrm{NH}_{2}{ }^{*} \mathrm{DPPD}\right)$

A solution of 1,3-diphenyl-1,3-propanedione (DPPD, $0.893 \mathrm{mmol})$ in anhydrous ethanol $(30 \mathrm{~mL})$ was added to $1 \mathrm{~g}$ of the synthesized $\mathrm{SiO}_{2} * \mathrm{NH}_{2}$ compound. The suspension was refluxed for $24 \mathrm{~h}$ at 85 $\pm 1{ }^{\circ} \mathrm{C}$ and filtered. The pale yellow powder was repeatedly washed with ethanol, and then Soxhlet extracted with ethanol and DCM, respectively, for $12 \mathrm{~h}$ to remove any unreacted DPPD. It was then vacuum dried at $70{ }^{\circ} \mathrm{C}\left( \pm 1^{\circ} \mathrm{C}\right)$.

Metalation of Schiff's base functionalized silica hybrid by $\mathrm{Cu}(\mathrm{II})\left(\mathrm{SiO}_{2}{ }^{*} \mathrm{NH}_{2}{ }^{*} \mathrm{DPPD}{ }^{*} \mathrm{Cu}\right)$

The copper(II)-incorporated hybrid was prepared by refluxing a mixture of anhydrous $\mathrm{CuCl}_{2}$ $(0.508 \mathrm{mmol})$ and $\mathrm{SiO}_{2} * \mathrm{NH}_{2} *$ DPPD $(1 \mathrm{~g})$ in anhydrous ethanol $(20 \mathrm{~mL})$ at $85 \pm 1{ }^{\circ} \mathrm{C}$ for $24 \mathrm{~h}$. The obtained dark green colored solid material was filtered and then Soxhlet extraction was performed with ethanol and DCM, respectively. The product was further dried at $70{ }^{\circ} \mathrm{C}\left( \pm 1{ }^{\circ} \mathrm{C}\right)$ under vacuum. The steps for the synthesis of $\mathrm{Cu}(\mathrm{II})$-hybrid is depicted in Scheme 1.

\section{Catalytic evaluation}

The catalytic activities of the as-synthesized $\mathrm{Cu}$ (II)-hybrid were evaluated by oxidative degradation of aqueous solution of RB5 and oxidation of organic substrates, i.e., tetralin, cycloalkane, and cycloalcohols.

\section{Batch reaction procedure for dye degradation}

Dye degradation experiment was performed by catalyzing aqueous solution of reactive black 5 (RB5) dye. A 500-mL solution of RB5 (45 ppm) 

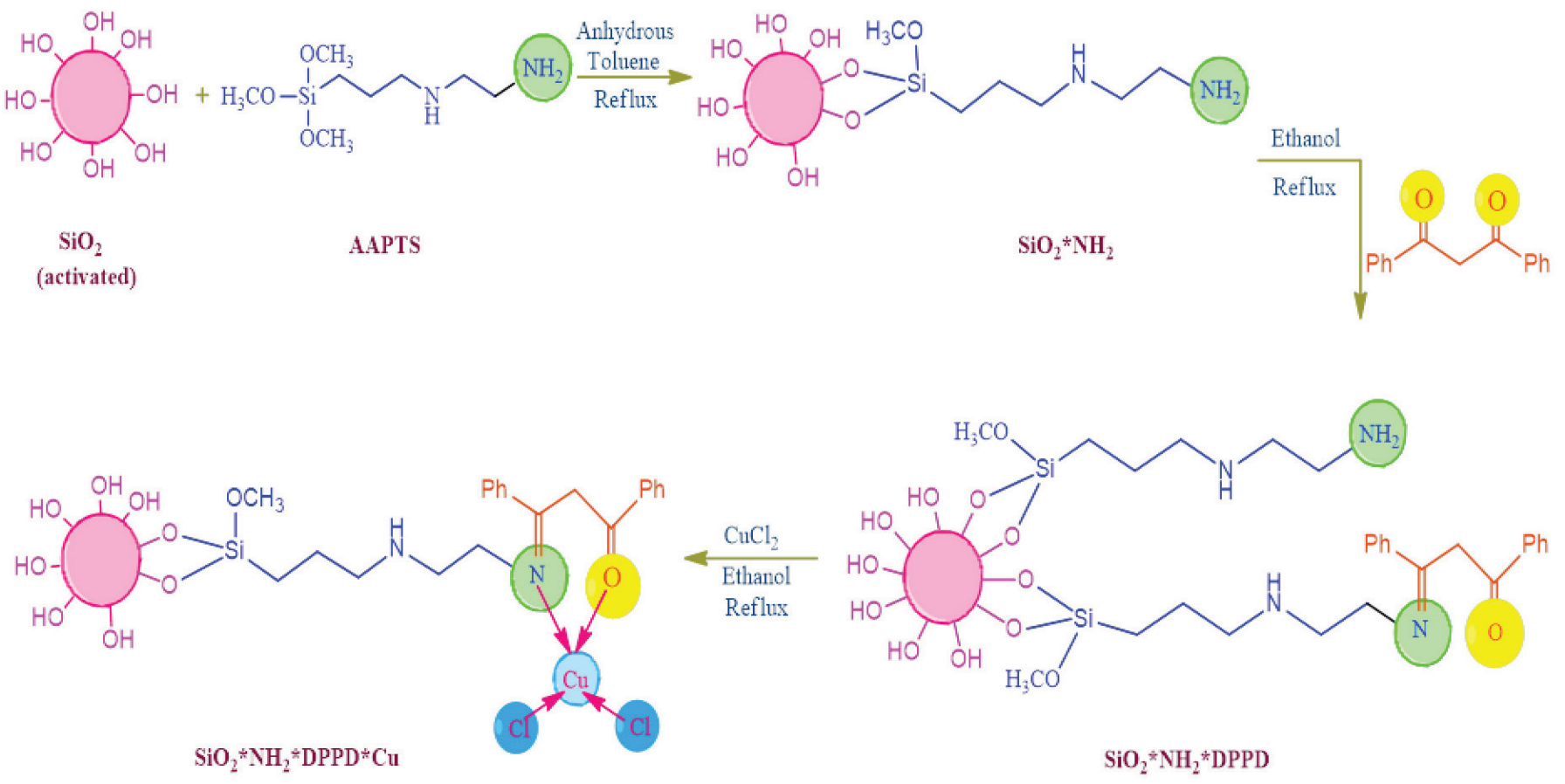

Scheme 1 -Steps for the synthesis of Cu (II)-hybrid

was prepared in Milli-Q water. The experiment was executed by mixing $25 \mathrm{~mL}$ of RB5 dye solution and $2 \mathrm{~mL}$ of $\mathrm{H}_{2} \mathrm{O}_{2}$ (4.41 mM, $8.82 \mathrm{mM}, 17.6 \mathrm{mM}$ and $26.46 \mathrm{mM})$. Hybrid catalyst $\left(0.2 \mathrm{~g} \mathrm{~L}^{-1}, 0.4 \mathrm{~g} \mathrm{~L}^{-1}\right.$, $0.6 \mathrm{~g} \mathrm{~L}^{-1}, 0.8 \mathrm{~g} \mathrm{~L}^{-1}$ and $1.0 \mathrm{~g} \mathrm{~L}^{-1}$ ) was added to this solution. These experiments were conducted at $35 \pm$ $1{ }^{\circ} \mathrm{C}$. One-factor-at-a-time optimization was performed resulting in the optimum concentration of hybrid catalyst of $0.8 \mathrm{~g} \mathrm{~L}^{-1}$, and $\mathrm{H}_{2} \mathrm{O}_{2}$ concentration of $17.6 \mathrm{mM}$. Finally, with the optimum concentrations of the $\mathrm{H}_{2} \mathrm{O}_{2}$ (i.e., $17.6 \mathrm{mM}$ ), and catalyst (i.e., $\left.0.8 \mathrm{~g} \mathrm{~L}^{-1}\right)$, experiments were also performed at (45 and 55) $\pm 1{ }^{\circ} \mathrm{C}$.

All batch reaction experiments were performed at $35 \pm 1{ }^{\circ} \mathrm{C}$ while continuously stirring with a magnetic stirrer at the speed of $1200 \mathrm{rpm}$. Each time an aliquot $(2 \mathrm{~mL})$ was withdrawn from the reaction mixture and filtered. The solution was then tested for remaining concentration of RB5 by monitoring its characteristic peak at absorption maximum $\left(\lambda_{\max }\right)$ $=596 \mathrm{~nm}$, which decreased as the reaction proceeded. Control experiments were also executed to observe the individual effect of $\mathrm{H}_{2} \mathrm{O}_{2}$ and catalysts. For this, degradation experiment was performed with $\mathrm{H}_{2} \mathrm{O}_{2}$ only, and another experiment with catalyst only, keeping other experimental conditions as before.

Dye degradation percentage was calculated using following formula:

Dye degradation $\left.(\%)=\left[\left(C_{\mathrm{RB} 5}\right)_{0}-\left(C_{\mathrm{RB} 5}\right)_{t}\right) /\left(C_{\mathrm{RB} 5}\right)_{0}\right] \cdot 100 \%$ where, $\left(C_{\mathrm{RB} 5}\right)_{0}$ and $\left(C_{\mathrm{RB} 5}\right)_{t}$ are initial and time-dependent concentrations of dye solutions.
Batch reaction procedure for oxidation of organic substrates

For oxidation of organic substrates (i.e.; tetralin, cyclohexane, and cycloalcohols,), reaction was carried out by taking $5 \mathrm{mM}$ substrate, $1 \mathrm{~mL} \mathrm{H}_{2} \mathrm{O}_{2}$ (17.6 mM) as oxidant, acetonitrile (solvent), and $0.02 \mathrm{~g}$ catalyst in a $100-\mathrm{mL}$ reaction vessel. The mixture was refluxed at $70{ }^{\circ} \mathrm{C}\left( \pm 1{ }^{\circ} \mathrm{C}\right)$ for $4 \mathrm{~h}$ with continuous stirring by a magnetic stirrer at the speed of $1200 \mathrm{rpm}$. After $4 \mathrm{~h}$, the mixture was diluted with Milli-Q water and products were extracted by DCM. The catalyst was separated and products were analyzed by GC-MS. The conditions for catalytic oxidation of organic substrates were initially optimized to obtain best procedure. The optimization was done in terms of various solvents (glacial acetic acid, dimethyl sulfoxide, dimethylformamide, and acetonitrile), different temperatures $\left(40^{\circ} \mathrm{C}, 50^{\circ} \mathrm{C}\right.$, $60{ }^{\circ} \mathrm{C}$ and $70{ }^{\circ} \mathrm{C}$ ), and different catalyst amounts $(0.01 \mathrm{~g}, 0.02 \mathrm{~g}$ and $0.03 \mathrm{~g})$; keeping other parameters same as previously mentioned, i.e., $5 \mathrm{mM}$ substrate (tetralin was chosen as reference substrate) and $1 \mathrm{~mL} \mathrm{H}_{2} \mathrm{O}_{2}(17.6 \mathrm{mM})$.

\section{Study of reusability and stability of the catalyst}

For performing reusability tests, the catalyst from previous experiment was washed with ethanol several times, and dried at $70{ }^{\circ} \mathrm{C}\left( \pm 1^{\circ} \mathrm{C}\right)$ in an oven. The reusability of the catalyst was investigated by degrading fresh solution of RB5 and oxidizing tetralin under best reaction conditions. The procedure for the catalytic study was the same as earlier. 
The stability of catalysts was inspected by observing the leaching content of metal ions. For executing the leaching experiment, same model reaction for dye degradation experiment $(17.6 \mathrm{mM}$ $\mathrm{H}_{2} \mathrm{O}_{2}, 0.8 \mathrm{~g} \mathrm{~L}^{-1}$ catalyst and $35 \pm 1{ }^{\circ} \mathrm{C}$ temperature) was performed for 30 minutes. The heterogeneous catalysts were then removed by filtration. The filtrates were allowed to react further for 60 minutes, and examined for dye degradation percentage.

The stability of the catalyst was also checked by analyzing the fresh and used hybrid through FTIR and SEM analyses. For this, the hybrid used in the dye degradation experiment was separated through filtration, washed several times with ethanol, and dried at $70{ }^{\circ} \mathrm{C}\left( \pm 1^{\circ} \mathrm{C}\right)$ in an oven.

\section{Results and discussion}

\section{Characterization of the catalyst}

\section{FT-IR spectra}

FT-IR spectra of silica based hybrid materials are illustrated in Fig. 1. FT-IR spectrum of $\mathrm{SiO}_{2}$ (Fig. 1a) exhibited its distinct peaks at $3442 \mathrm{~cm}^{-1}$ and $1639 \mathrm{~cm}^{-1}$ due to surface silanol $(\mathrm{Si}-\mathrm{OH})$ stretching and bending vibrations, respectively. The band at $1091 \mathrm{~cm}^{-1}$ was due to asymmetric and that at $795 \mathrm{~cm}^{-1}$ was due to symmetric vibrations of $\mathrm{Si}-\mathrm{O}-\mathrm{Si}$ bond; and the band at $461 \mathrm{~cm}^{-1}$ was attributed to $\mathrm{Si}-\mathrm{O}-\mathrm{Si}$ bending vibrations. In the spectrum of $\mathrm{SiO}_{2} * \mathrm{NH}_{2}$ (Fig. 1b), some new peaks appeared. The bands at $2905 \mathrm{~cm}^{-1}$ and $2851 \mathrm{~cm}^{-1}$ were attributed to the vibrations of $\mathrm{C}-\mathrm{H}$ stretch and 1490 $\mathrm{cm}^{-1}$ to bending vibrations of $\mathrm{C}-\mathrm{H}$ bond. The characteristic band in the region of $3000-3300 \mathrm{~cm}^{-1}$ for $\mathrm{NH}_{2}$ stretching vibration was not clearly resolved in the FT-IR spectrum of the organo-functionalized silica gel. However, the band in the region of 3400 $3500 \mathrm{~cm}^{-1}$ was due to $\mathrm{O}-\mathrm{H}$ stretching vibration and exhibited deformation which may be assigned to unresolved $\mathrm{N}-\mathrm{H}$ stretching vibration of $\mathrm{SiO}_{2}{ }^{*} \mathrm{NH}_{2}$. The presence of $\mathrm{NH}_{2}$ group in the grafted $\mathrm{SiO}_{2} * \mathrm{NH}_{2}$ was further evidenced by an additional band at 1551 $\mathrm{cm}^{-1}$ assigned to of $\mathrm{NH}_{2}$ bending vibration ${ }^{28}$. Grafting of AAPTS on the surface of silica was also confirmed through the shift observed in $\mathrm{O}-\mathrm{H}$ stretching vibration, which shifted to lower wave number. Fig. 1c represents the FT-IR spectrum of Schiff's base formation on $\mathrm{SiO}_{2}{ }^{*} \mathrm{NH}_{2}$ grafted moiety. In the spectrum of $\mathrm{SiO}_{2} * \mathrm{NH}_{2}{ }^{*}$ DPPD, new peak at $1668 \mathrm{~cm}^{-1}$ was observed, which characterized $\mathrm{C}=\mathrm{N}$ stretching ${ }^{29}$ and confirmed the formation of Schiff base as a result of reacting $\mathrm{SiO}_{2}{ }^{*} \mathrm{NH}_{2}$ and DPPD. Appearance of less intense bands at $1400-1500 \mathrm{~cm}^{-1}$ was attributed to aromatic rings stretching vibrations of DPPD. An additional band at $1728 \mathrm{~cm}^{-1}$ observed due to presence of $\mathrm{C}=\mathrm{O}$ group, indicating that one of the $\mathrm{C}=\mathrm{O}$ groups of DPPD did not participate in the Schiff base reaction. On metalation with copper(II) chloride, the $\mathrm{C}=\mathrm{N}\left(1668 \mathrm{~cm}^{-1}\right)$ and $\mathrm{C}=\mathrm{O}$ $\left(1728 \mathrm{~cm}^{-1}\right)$ vibrations were shifted to 1636 and $1691 \mathrm{~cm}^{-1}$ respectively, i.e., to the lower wave number region, therefore confirming the coordination of metal ions through these groups (Fig. 1d). Further, the newly observed bands at 442 and $605 \mathrm{~cm}^{-1}$

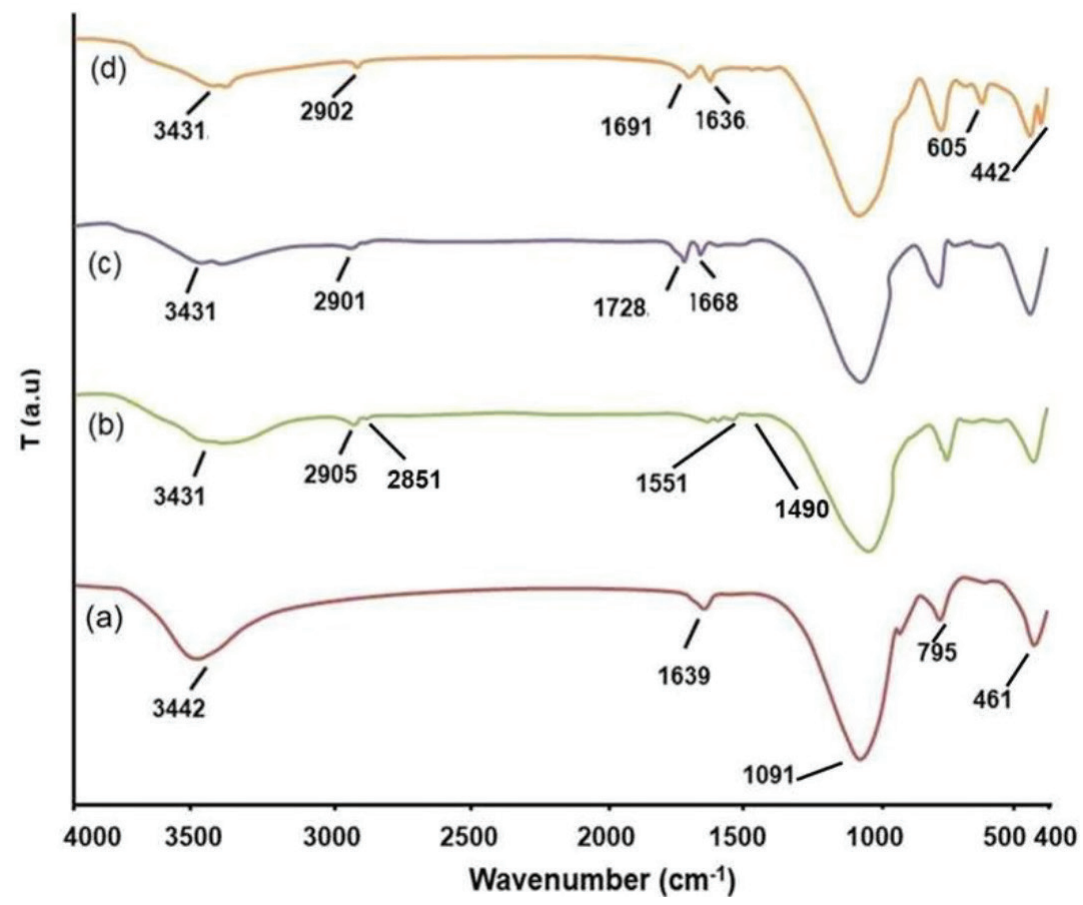

Fig. 1 - Comparative FT-IR spectra for (a) $\mathrm{SiO}_{2}$, (b) $\mathrm{SiO}_{2} * \mathrm{NH}_{2}$, (c) $\mathrm{SiO}_{2}{ }^{*} \mathrm{NH}_{2} * \mathrm{DPPD}$, and (d) $\mathrm{SiO}_{2} * \mathrm{NH}_{2}{ }^{*} \mathrm{DPPD} \mathrm{CH}^{*} \mathrm{Cu}$ 
might be assigned to stretching vibrations of $\mathrm{Cu}-\mathrm{N}$ and $\mathrm{Cu}-\mathrm{O}$ bonds, respectively ${ }^{30}$. This also supported the assumption that copper metal was coordinated with nitrogen of imine group and oxygen of $\mathrm{C}=\mathrm{O}$ group of DPPD. The Metal-Cl vibrations generally occurred below $400 \mathrm{~cm}^{-1}$ and therefore could not be found in the spectrum.

\section{Diffuse reflectance UV-Visible (DRUV-Vis) spectroscopy}

Existence of organic functional groups in the synthesized materials was also confirmed through DRUV-Vis spectra, which are shown in Fig. 2. The electronic absorption spectrum of $\mathrm{SiO}_{2}$ showed no absorption in the range of $200-800 \mathrm{~nm}$, while that of $\mathrm{SiO}_{2} * \mathrm{NH}_{2}$ exhibited a band below $300 \mathrm{~nm}$, which might be due to $n-\sigma^{*}$ transition of non-bonded electrons of $\mathrm{NH}_{2}$ (Fig. 2b). After Schiff's base formation of grafted aminopropyl silica by DPPD, a band was observed around $250 \mathrm{~nm}$ in the UV-visible spectrum of $\mathrm{SiO}_{2} * \mathrm{NH}_{2}{ }^{*} \mathrm{DPPD}$, which could be a result of $\pi-\pi^{*}$ electronic transition of phenyl ring. Absorbance peak near $360 \mathrm{~nm}$ might be assigned to $n-\pi^{*}$ transition of $\mathrm{C}=\mathrm{N}$ non-bonded electrons, confirming the grafting of DPPD to the aminopropylsilica (Fig. $2 \mathrm{c}$ ). The spectrum of $\mathrm{Cu}(\mathrm{II})$ metalated hybrid (Fig. 2d) also exhibited the $n-\pi^{*}$ and $\pi-\pi^{*}$ transition peaks, but they were shifted to higher wavelength suggesting the coordination of ligands to the $\mathrm{Cu}$ (II) ion. The low intensity band around $600 \mathrm{~nm}$ in the electronic spectrum of $\mathrm{Cu}(\mathrm{II})$-hybrid (Fig. 2 inset) was assigned to ${ }^{2} \mathrm{~B}_{1 \mathrm{~g}} \rightarrow{ }^{2} \mathrm{~A}_{1 \mathrm{~g}}$ transition, characteristic of square planar geometry ${ }^{39}$.

\section{Solid state ${ }^{13} \mathrm{C} C$ CPMAS NMR spectroscopy}

Functionalization of silica surface with AAPTS and formation of Schiff base was confirmed by Solid state ${ }^{13} \mathrm{C}$ NMR spectra (Fig. 3a). The peak at $9.861 \mathrm{ppm}$ was assigned to the most shielded carbon atom $(\mathrm{C} 1)$ due to its attachment with silicon atom. Peak at $23.016 \mathrm{ppm}$ was due to $-\mathrm{CH}_{2}$ - group (C2), and those at $36.632 \mathrm{ppm}(\mathrm{C} 3)$ and 38.714 ppm (C4) were designated to carbon atoms bound to $-\mathrm{NH}-$ group. Signal at $45.788 \mathrm{ppm}$ was due to the carbon atom (C5) attached to amino group. Peak at $50.896 \mathrm{ppm}$ was attributed to unsubstituted methoxy group ${ }^{32}$. Presence of these peaks confirmed that AAPTS had been successfully grafted on silica surface.

In the $\mathrm{SiO}_{2}{ }^{*} \mathrm{NH}_{2}{ }^{*} \mathrm{DPPD}$ spectrum, fourteen well resolved peaks were obtained (Fig. 3b). Signals at $\delta=11.041,22.406,36.141,39.327$, and $52.059 \mathrm{ppm}$ were assigned to $\mathrm{C} 1, \mathrm{C} 2, \mathrm{C} 3, \mathrm{C} 4$, and $\mathrm{C} 7$ respectively. $\mathrm{N}-\mathrm{CH}_{2}$ peak shifted to $57.699 \mathrm{ppm}$ (C6) on Schiff's base formation, while the signal at $45.416 \mathrm{ppm}$ (C5) was assigned to unreacted (free) $-\mathrm{N}-\mathrm{CH}_{2}$ group. Signal at $168.194 \mathrm{ppm}$ was due to $\mathrm{C}=\mathrm{N}$ group, which further supported the Schiff's base formation. Peak at $\delta=186.652 \mathrm{ppm}$ was attributed to $\mathrm{C}=\mathrm{O}$ group, thereby indicating the non-involvement of one carbonyl group in the Schiff base reaction. C-9 gave the signal at 29.926 ppm. Peaks at 134.780 and 140.506 ppm were assigned to aromatic carbon atoms of phenyl rings attached to carbonyl group and imine group, respectively. Peaks at 128.628 and $122.646 \mathrm{ppm}$ were due to remaining phenyl carbon atoms ( $\mathrm{C}-\mathrm{a}$ to $\mathrm{C}-\mathrm{f})$,

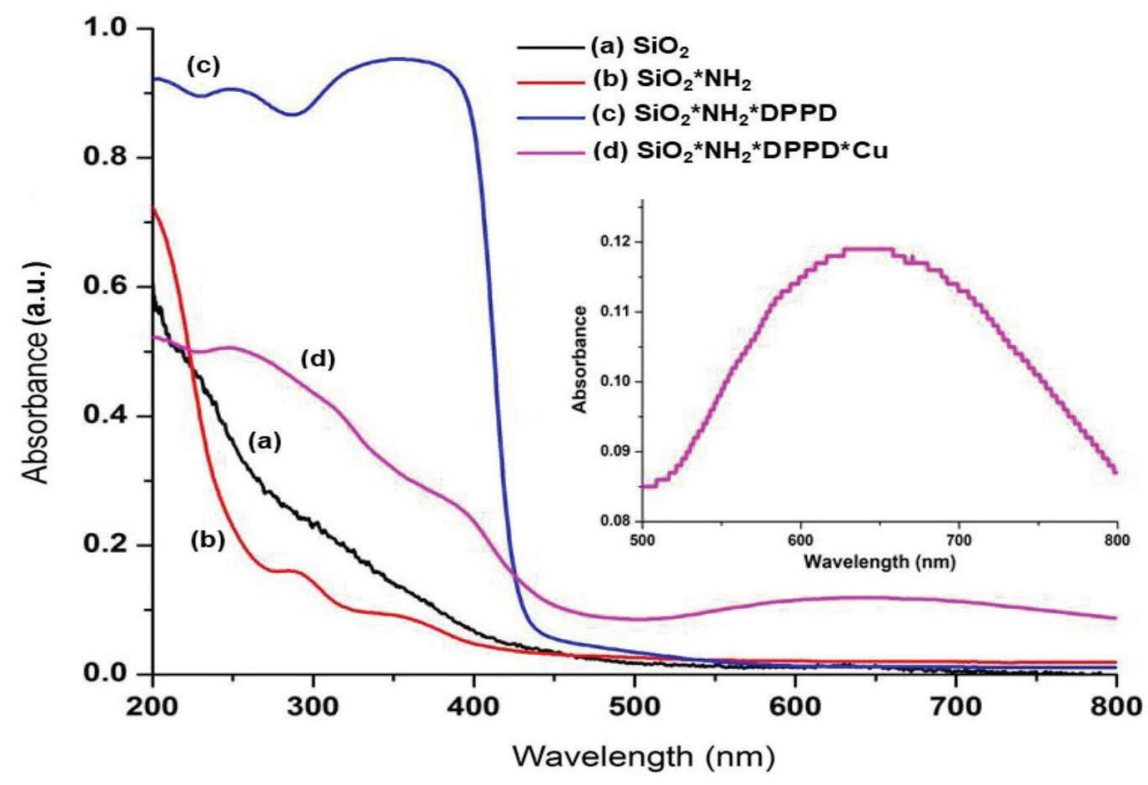

Fig. 2 - DRUV-Visible spectra of (a) $\mathrm{SiO}_{2}$ gel, (b) $\mathrm{SiO}_{2}{ }^{*} \mathrm{NH}_{2}$, (c) $\mathrm{SiO}_{2}{ }^{*} \mathrm{NH}_{2}{ }^{*} \mathrm{DPPD}$, (d) $\mathrm{SiO}_{2}{ }^{*} \mathrm{NH}_{2}{ }^{*} \mathrm{DPPD} * \mathrm{Cu}$. The inset shows the spectrum of $\mathrm{SiO}_{2}{ }^{*} \mathrm{NH}_{2}{ }^{*} \mathrm{DPPD}{ }^{*} \mathrm{Cu}$ in the range of $500-800 \mathrm{~nm}$. 


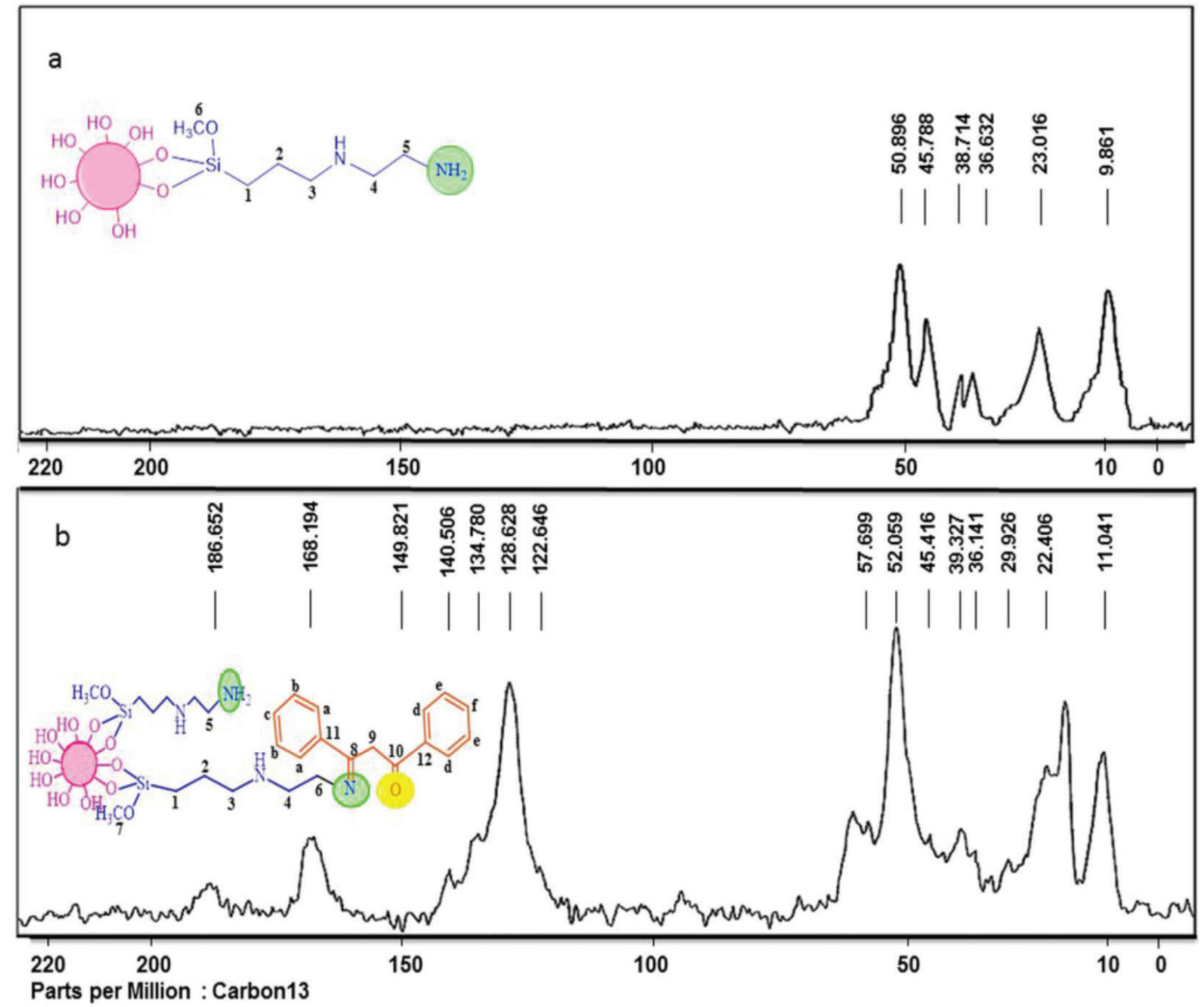

Fig. 3 - Solid state ${ }^{13} \mathrm{C} N \mathrm{NM}$ spectra of (a) $\mathrm{SiO}_{2}{ }^{*} \mathrm{NH}_{2}$, (b) $\mathrm{SiO}_{2}{ }^{*} \mathrm{NH}_{2}{ }^{*} \mathrm{DPPD}$

which should have been resolved into six peaks but resolution of these peaks were not achieved in solid state NMR spectrum.

\section{Powder-XRD}

Powder XRD analysis of all the relevant materials obtained after each step is exemplified in Fig. 4. A broad peak around $2 \theta=22^{\circ}$ had been observed in the XRD pattern of $\mathrm{SiO}_{2}$, a distinguishing feature of topological structure of silica ${ }^{7,27}$. This distinctive peak was also observed in the graph of the rest of the synthesized compounds, Fig. S1 (Supplementary Information).

\section{SEM}

SEM micrographs of $\mathrm{SiO}_{2}$ gel and its modified forms are delineated in Fig. S2 (Supplementary Information). As seen from SEM micrograph, the ungrafted silica $\left(\mathrm{SiO}_{2}\right)$ particles had irregular shape, which they retained after modification. It was also observed that, after successive modifications, sur- face became slightly rough, which might have been due to the attachment of organic groups.

ICP-AES (Inductively coupled plasma atomic emission spectroscopy) and EDX (energy dispersive X-ray) analysis

EDX analysis of the $\mathrm{Cu}(\mathrm{II})$-hybrid is depicted in Fig. 4 illustrating the presence of all expected elements, thereby indicating the formation of $\mathrm{Cu}(\mathrm{II})$-hybrid. To support the presence of copper and find its coordinated amount, ICP-AES investigation of the hybrid catalyst was executed. In the analysis, weight $\%$ of $\mathrm{Cu}$ was found to be $2.352 \%$ and is almost similar to the EDX result which further supported the proposed structure for the hybrid. Also, as per EDX analysis, $0.804 \mathrm{mmol}$ AAPTS, $0.458 \mathrm{mmol} \mathrm{Cu}$, and $0.625 \mathrm{mmol}$ of $\mathrm{Cl}$ are bonded to one gram of the sample.

\section{Thermogravimetric analysis (TGA)}

Thermal behavior of the synthesized materials was investigated by TGA (Fig. 5). $\mathrm{SiO}_{2}$ exhibited a 


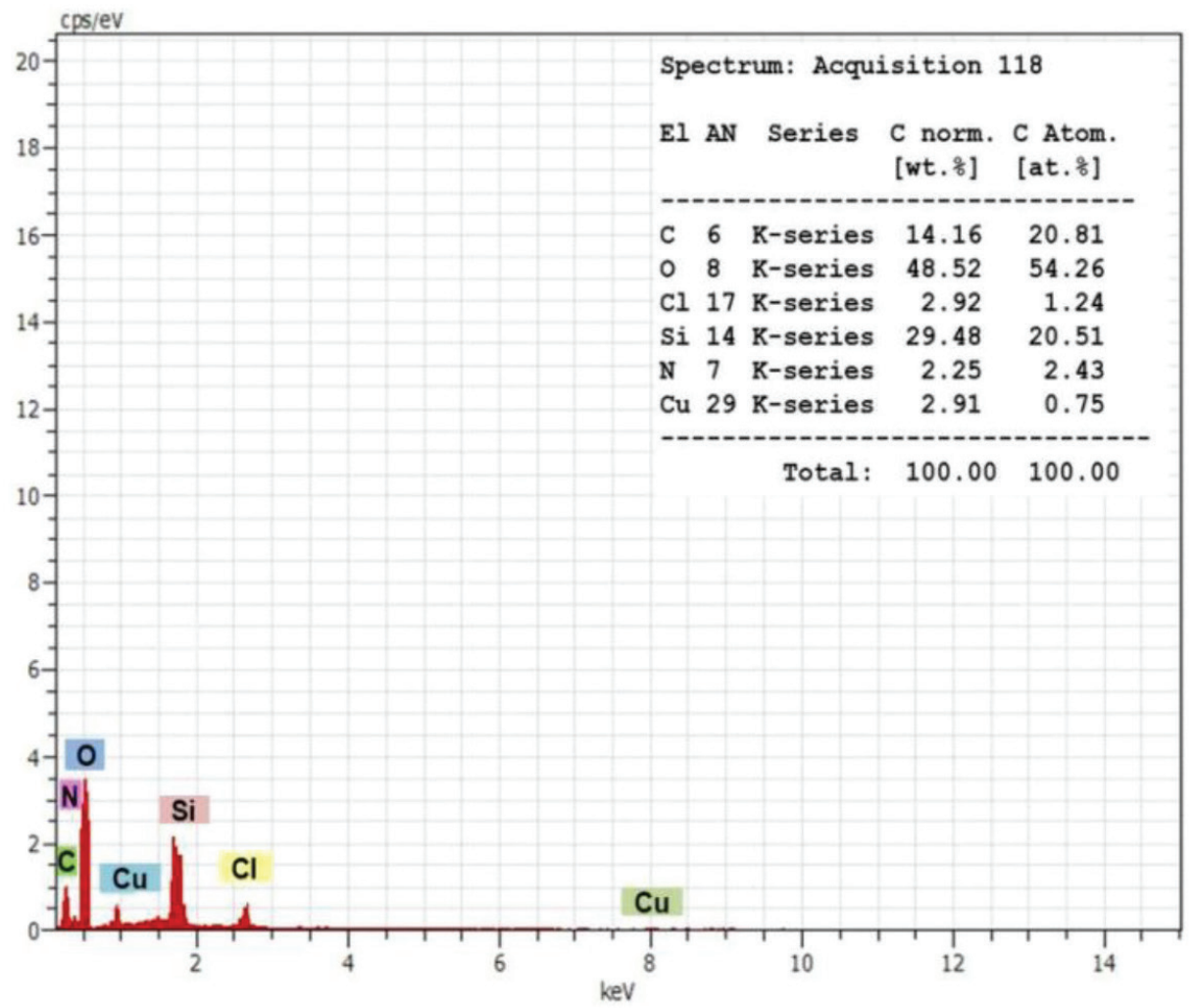

Fig. $4-$ EDX spectrum of $\mathrm{SiO}_{2} * \mathrm{NH}_{2}{ }^{*} \mathrm{DPPD} * \mathrm{Cu}$

minor weight loss of approximately $5 \%$ in the entire temperature scan (Fig. 5a). The weight loss in the range of $100-120{ }^{\circ} \mathrm{C}$ might be attributed to the removal of physically adsorbed molecules of water, indicating the hydrophilic nature of silica matrix ${ }^{33}$. The TGA curve of $\mathrm{SiO}_{2} * \mathrm{NH}_{2}$ (Fig. 5b) showed a total weight loss of $15 \%$. The first decomposition peak $\left(100-130^{\circ} \mathrm{C}\right)$ was attributed to the loss of ad-

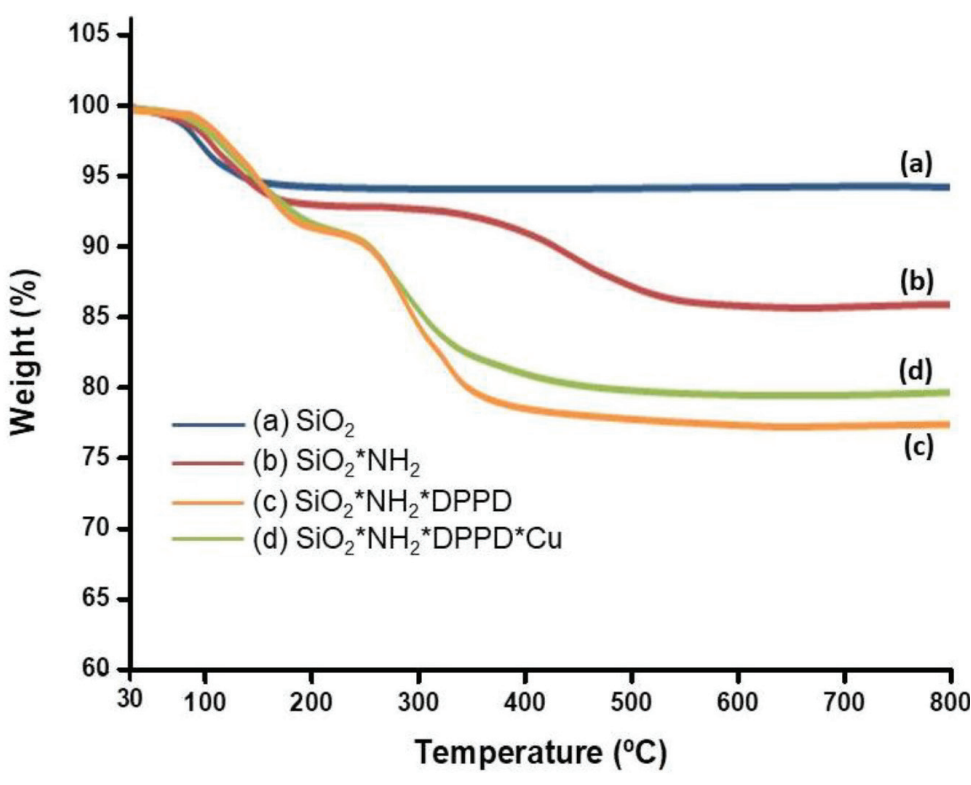

Fig. 5 - TG curves of (a) $\mathrm{SiO}_{2}$ gel, (b) $\mathrm{SiO}_{2}{ }^{*} \mathrm{NH}_{2}$, (c) $\mathrm{SiO}_{2}{ }^{*}$ $\mathrm{NH}_{2}{ }^{*} \mathrm{DPPD}$, (d) $\mathrm{SiO}_{2}{ }^{*} \mathrm{NH}_{2}{ }^{*} \mathrm{DPPD}{ }^{*} \mathrm{Cu}$ sorbed water molecules, and the second one (390$510^{\circ} \mathrm{C}$ ) to the decomposition of chemically bonded AAPTS, revealing therefore, the grafting of approximately $0.99 \mathrm{mmol}$ AAPTS per gram of $\mathrm{SiO}_{2}$. Thermogram of $\mathrm{SiO}_{2}{ }^{*} \mathrm{NH}_{2}{ }^{*} \mathrm{DPPD}$ (Fig. 5c) illustrated a higher total weight loss of $23 \%$ where the decomposition peak at $250-340{ }^{\circ} \mathrm{C}$ could be due to the loss of DPPD molecules. The TGA analysis showed the loading of approximate $0.53 \mathrm{mmol} \mathrm{DPPD} / \mathrm{g}$ $\mathrm{SiO}_{2} * \mathrm{NH}_{2} \cdot \mathrm{Cu}(\mathrm{II})$-hybrid $\left(\mathrm{SiO}_{2} * \mathrm{NH}_{2}^{*} \mathrm{DPPD} * \mathrm{Cu}\right)$ showed a weight loss of approximately $21 \%$ (Fig. $5 \mathrm{~d})$. Since the metal ion on heating in the presence of oxygen from the organic moiety is converted to metal oxide and remains present on the solid matrix, the overall \% weight loss decreases slightly, i.e., from 23 to 21 . The mean degradation temperature for the thermogram had shifted to higher side, which could be attributed to the silica silane-Schiff's base stabilization by metalation (Fig. 5d). The weight loss observed from the thermogram of $\mathrm{Cu}$ (II)-hybrid revealed an approximate attachment of $0.346 \mathrm{mmol} \mathrm{Cu} / \mathrm{g} \mathrm{SiO}{ }_{2}^{*} \mathrm{NH}_{2}{ }^{*} \mathrm{DPPD}$, which is close to EDX result, i.e., $0.458 \mathrm{mmol} \mathrm{Cu}$ per gram of the sample.

\section{Electron paramagnetic resonance (EPR) spectrum}

The powder X-band EPR spectrum of $\mathrm{Cu}$ (II)-hybrid at room temperature is shown in Fig. S3 (Supplementary Information). The EPR spectrum is typical of a normal axial monomeric $\mathrm{Cu}$ 
species with $\mathrm{d}_{\mathrm{x}-\mathrm{y}}^{2}{ }^{2}$ as ground state. On comparing the calculated $\mathrm{g}$ factors, it was found that $\mathrm{g}$ factors were in order of $g_{\text {II }}(2.2881)>g_{\perp}(2.0596)>2.0023$, indicating the presence of unpaired electron in $\mathrm{d}_{\mathrm{x}-\mathrm{y}}^{2}$ orbital $^{7}$. This suggested the geometry of the compound to be square planar. Generally, the perpendicular feature of the spectrum comprised of a series of closely spaced, overlapping lines, appearing as a result of coupling of unpaired electron with copper nucleus, which could not be resolved at room temperature. From the spin Hamiltonian parameters, it appeared that the system was very likely to be square planar. Square planar geometry of the $\mathrm{Cu}(\mathrm{II})$-hybrid is also in agreement with the DRUVVis spectrum.

It is reported that $\mathrm{g}_{\mathrm{II}}>2.3$ represents ionic environment, and $\mathrm{g}_{\mathrm{II}}<2.3$ indicates considerable covalent character in the metal-ligand bonding ${ }^{34}$. The $\mathrm{g}_{\mathrm{II}}$ value obtained from the spectrum of $\mathrm{Cu}(\mathrm{II})$-hybrid was less than 2.3, thereby suggesting the possible covalent character of the $\mathrm{Cu}$-ligand bond. The $\mathrm{g}_{\mathrm{av}}$ value was calculated from $\mathrm{g}_{\mathrm{av}}{ }^{2}=\left(\mathrm{g}_{\mathrm{II}}{ }^{2}+2 \mathrm{~g}_{\perp}{ }^{2}\right) / 3$, giving the value of 2.13 for the hybrid. Its deviation from the g-value of free electron (2.0023) might be due to covalent character in the metal-ligand bond ${ }^{35}$. The exchange coupling factor $(\mathrm{G})$ was calculated using following formula ${ }^{7}$ :

$$
\mathrm{G}=\left[\left(g_{\mathrm{II}}-2\right) /\left(g_{\perp}-2\right)\right]
$$

If $\mathrm{G}>4$, it denotes parallel aligned or slightly misaligned local axes with negligible exchange coupling; and if $\mathrm{G}<4$, it symbolizes remarkably misaligned local axes with considerable exchange coupling ${ }^{7}$. Here, $\mathrm{G}$ value was calculated as 4.83 ,

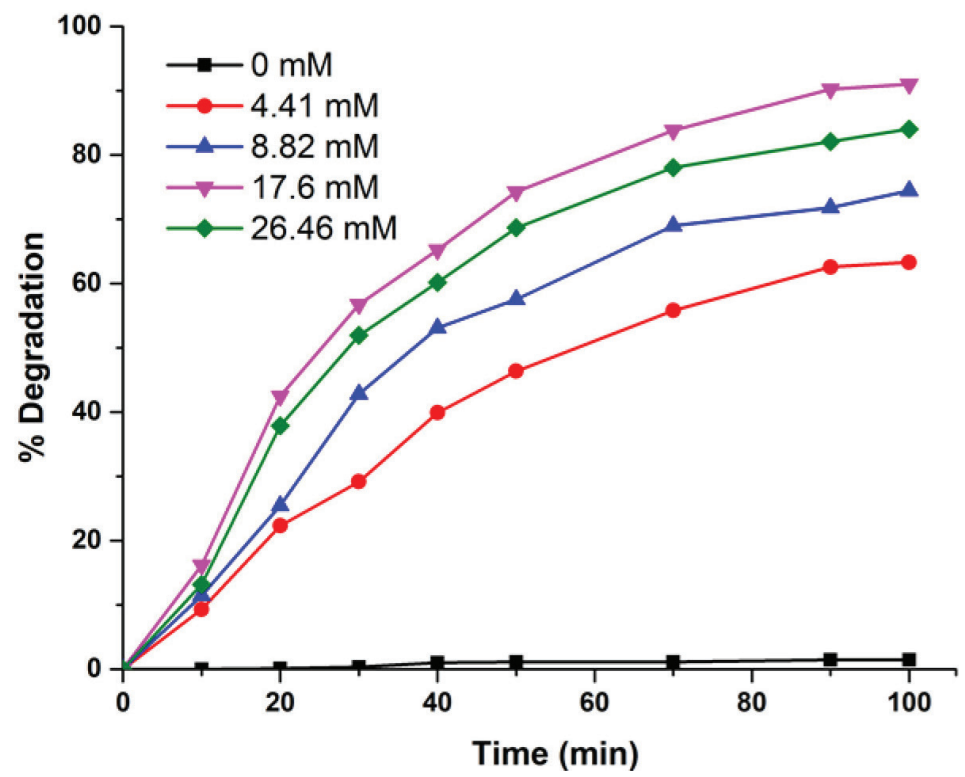

Fig. 6 - Effect of $\mathrm{H}_{2} \mathrm{O}_{2}$ concentration on degradation of $\mathrm{RB} 5$ (RB5 concentration $=45^{2} \mathrm{ppm}$, catalyst concentration $=0.8 \mathrm{gL}^{-1}$, temperature $=35 \pm 1{ }^{\circ} \mathrm{C}$ ) thus, having no copper-copper exchange interactions. Thus, it may be concluded that the present $\mathrm{Cu}(\mathrm{II})$-hybrid exhibited significant covalent character with no $\mathrm{Cu}(\mathrm{II})-\mathrm{Cu}$ (II) exchange. Additionally, small splitting in the perpendicular signal may be due to difference in bond length of $\mathrm{M}-\mathrm{O}, \mathrm{M}-\mathrm{N}$ and $\mathrm{M}-\mathrm{Cl}$ ligands.

\section{Catalytic evaluation}

\section{Oxidative degradation of RB5}

\section{Optimization of reaction conditions}

The process parameters were optimized in terms of effect of $\mathrm{H}_{2} \mathrm{O}_{2}$ concentration, catalyst concentration and reaction temperature to achieve a given output with best inputs.

\section{Effect of $\mathrm{H}_{2} \mathrm{O}_{2}$ concentration}

Effect of $\mathrm{H}_{2} \mathrm{O}_{2}$ concentration was investigated by varying its concentration from 0 to $26.46 \mathrm{mM}$, while maintaining other parameters constant, i.e., catalyst concentration at $0.8 \mathrm{~g} \mathrm{~L}^{-1}$ and temperature at $35 \pm 1{ }^{\circ} \mathrm{C}$. It was observed that dye degradation percentage at $(0,4.41,8.82,17.6$, and 26.46$) \mathrm{mM}$ $\mathrm{H}_{2} \mathrm{O}_{2}$ was $1 \%, 63 \%, 72 \%, 91 \%$, and $84 \%$, respectively (Fig. 6). Thus, degradation of RB5 showed acceleration up to $17.6 \mathrm{mM}$, but further increase in concentration of $\mathrm{H}_{2} \mathrm{O}_{2}$ decreased the degradation percentage. The enhancement in the degradation at beginning of reaction may have been due to increased generation of beneficial hydroxyl radicals $(\cdot \mathrm{OH})$, which acted as strong oxidizing agents and reacted with dyes, leading to their degradation ${ }^{36}$.

Several studies have reported $\mathrm{Cu}$-mediated homogeneous catalytic decomposition of hydrogen peroxide $^{37-39}$. Mechanism for $\mathrm{H}_{2} \mathrm{O}_{2}$ decomposition can be represented by a Fenton-like reaction, as given by Lin et al. ${ }^{40}$ (Eq.1-3), where L symbolizes the ligand used in their system.

$$
\begin{aligned}
& \mathrm{L}-\mathrm{Cu}{ }^{+}+\mathrm{H}_{2} \mathrm{O}_{2} \rightarrow \mathrm{Lu}-\mathrm{Cu} \mathrm{OOH}^{+}+\mathrm{H}^{+} \\
& \mathrm{L}-\mathrm{Cu}{ }^{\cdot} \mathrm{OOH}^{+} \rightarrow \mathrm{L}-\mathrm{Cu}^{+}+{ }^{\circ} \mathrm{O}_{2} \mathrm{H} \\
& \mathrm{L}-\mathrm{Cu}^{+}+\mathrm{H}_{2} \mathrm{O}_{2} \rightarrow \mathrm{L}-\mathrm{Cu}^{2+}+\mathrm{HO}^{-}+{ }^{\cdot} \mathrm{OH}
\end{aligned}
$$

This could be a possible mechanism for $\mathrm{H}_{2} \mathrm{O}_{2}$ decomposition in the present system.

Further, decrease in efficiency upon increasing $\mathrm{H}_{2} \mathrm{O}_{2}$ concentration might be due to scavenging of useful $\cdot \mathrm{OH}$ radicals and generation of hyperoxyl radicals $\left(\cdot \mathrm{O}_{2} \mathrm{H}\right)$, which are quite less reactive with no capability of degrading organic molecules. These $\cdot \mathrm{O}_{2} \mathrm{H}$ radicals further react with $\cdot \mathrm{OH}$ radical to form oxygen and water ${ }^{41}$. 


$$
\begin{gathered}
\mathrm{H}_{2} \mathrm{O}_{2}+{ }^{\cdot} \mathrm{OH} \rightarrow{ }^{\cdot} \mathrm{O}_{2} \mathrm{H}+\mathrm{H}_{2} \mathrm{O} \\
{ }^{\cdot} \mathrm{O}_{2} \mathrm{H}+{ }^{\cdot} \mathrm{OH} \rightarrow \mathrm{O}_{2}+\mathrm{H}_{2} \mathrm{O}
\end{gathered}
$$

As oxidation potential of $\cdot \mathrm{O}_{2} \mathrm{H}(1.78 \mathrm{~V})$ is less than that of $\cdot \mathrm{OH}$, self-scavenging cannot promote degradation of dye molecules ${ }^{42}$. Thus, effective dosage of $\mathrm{H}_{2} \mathrm{O}_{2}$ was taken as $17.6 \mathrm{mM}$ for further studies.

A very small amount of $\mathrm{H}_{2} \mathrm{O}_{2}$ was required to initiate the degradation process, and the dye degraded to very low extent in the absence of $\mathrm{H}_{2} \mathrm{O}_{2}$. In the presence of catalyst, the dye degraded to high extent, and therefore, it was very important to investigate whether the decline in the concentration of dye had occurred by adsorption of dye molecules on the surface of catalyst or by degradation through oxidative catalysis or by both. For this, a batch reaction was operated by taking $25 \mathrm{~mL}$ RB5 solution (45 $\mathrm{ppm})$ and synthesized catalyst $\left(0.8 \mathrm{~g} \mathrm{~L}^{-1}\right)$. The suspension was stirred for $4 \mathrm{~h}$ at $35 \pm 1{ }^{\circ} \mathrm{C}$. The decrease in $\lambda_{\text {max }}(596 \mathrm{~nm})$ was calculated by observations from UV-Vis spectra, and it was found to be only $3 \%$, Fig. S4 (Supplementary Information). Thus, it can be concluded that RB5 removal was not by adsorption but due to oxidative catalytic degradation by the $\mathrm{Cu}$ (II)-hybrid.

\section{Effect of catalyst concentration}

To examine the effect of catalyst concentration, experiments were carried out with different quantities of catalyst $(0.2,0.4,0.6,0.8$, and 1.0$) \mathrm{g} \mathrm{L}^{-1}$; keeping other parameters same, i.e., $\mathrm{H}_{2} \mathrm{O}_{2}$ concentration at $17.6 \mathrm{mM}$ and temperature at $35 \pm 1{ }^{\circ} \mathrm{C}$.

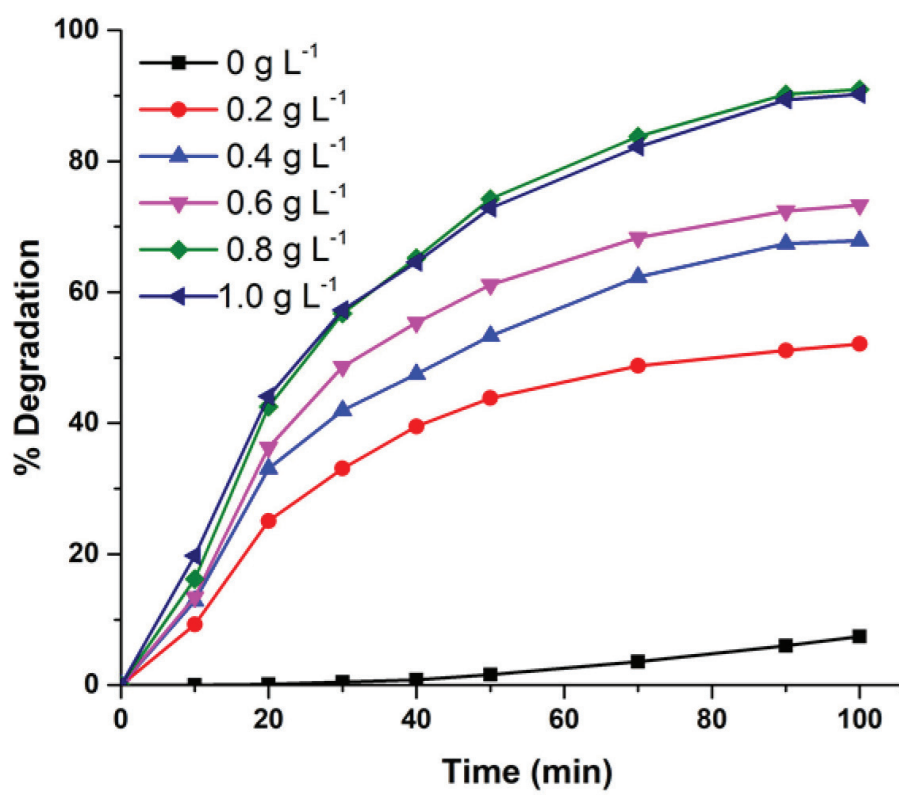

Fig. 7 - Effect of catalyst concentration on degradation of $R B 5\left(R B 5\right.$ concentration $=45 \mathrm{ppm}, \mathrm{H}_{2} \mathrm{O}_{2}$ concentration $=17.6$ $m M$, temperature $=35 \pm 1{ }^{\circ} \mathrm{C}$ )

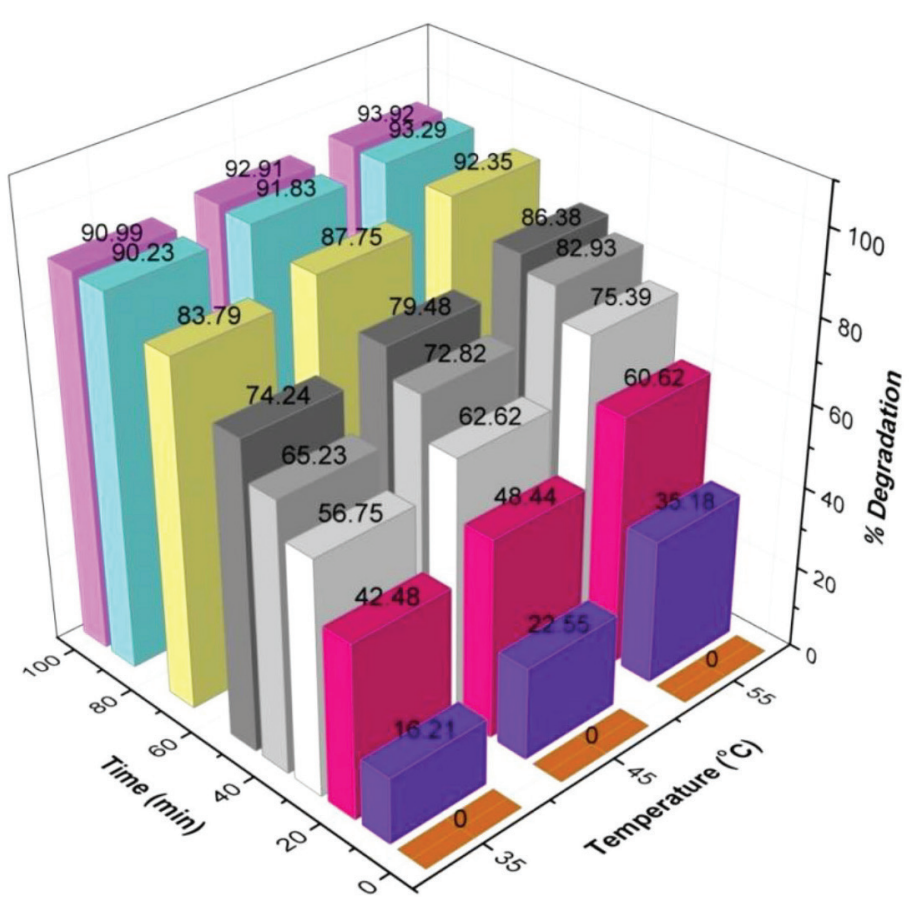

Fig. 8 - Effect of temperature on degradation of RB5 (RB5 concentration $=45 \mathrm{ppm}, \mathrm{H}_{2} \mathrm{O}_{2}$ concentration $=17.6 \mathrm{mM}$, catalyst concentration $\left.=0.8 \mathrm{~g} \mathrm{~L}^{-1}\right)$

Effect of catalyst concentration on RB5 degradation is presented in Fig. 7, from which it can be seen that degradation efficiency in the absence of catalyst was only $7 \%$ even after 100 minutes of reaction process. This efficiency increased to $52 \%, 68 \%$, $73 \%$, and $91 \%$ when catalyst was taken as $0.2 \mathrm{~g} \mathrm{~L}^{-1}$, $0.4 \mathrm{~g} \mathrm{~L}^{-1}, 0.6 \mathrm{~g} \mathrm{~L}^{-1}$ and $0.8 \mathrm{~g} \mathrm{~L}^{-1}$, respectively. This might be due to increase in more active sites for $\mathrm{H}_{2} \mathrm{O}_{2}$ molecules on catalyst surface. However, increasing the catalyst amount to $1.0 \mathrm{~g} \mathrm{~L}^{-1}$ did not improve the degradation efficiency significantly; possible reason may be that the increased amount of catalyst did not cause reaction between $\mathrm{H}_{2} \mathrm{O}_{2}$ molecules and active center (i.e., copper). Thus, $0.8 \mathrm{~g} \mathrm{~L}^{-1}$ was taken as best catalyst concentration.

The role of catalyst in the degradation of RB5 was also observed by performing the batch experiment in the presence of unmodified silica gel instead of catalyst. Here, degradation was only $10 \%$ even after 3 h, Fig. S5 (Supplementary Information). This result proved that the catalyst showed high activity towards RB5 degradation.

\section{Effect of temperature}

RB5 degradation was significantly influenced by the change in temperature and percentage degradation of dye with time at different temperatures $\left(35,45,55^{\circ} \mathrm{C}\right) \pm 1{ }^{\circ} \mathrm{C}$, as shown in Fig. 8. It was observed that dye degradation percentage increased with time. Also observed was that degradation of RB5 dye increased with temperature, as expected. 


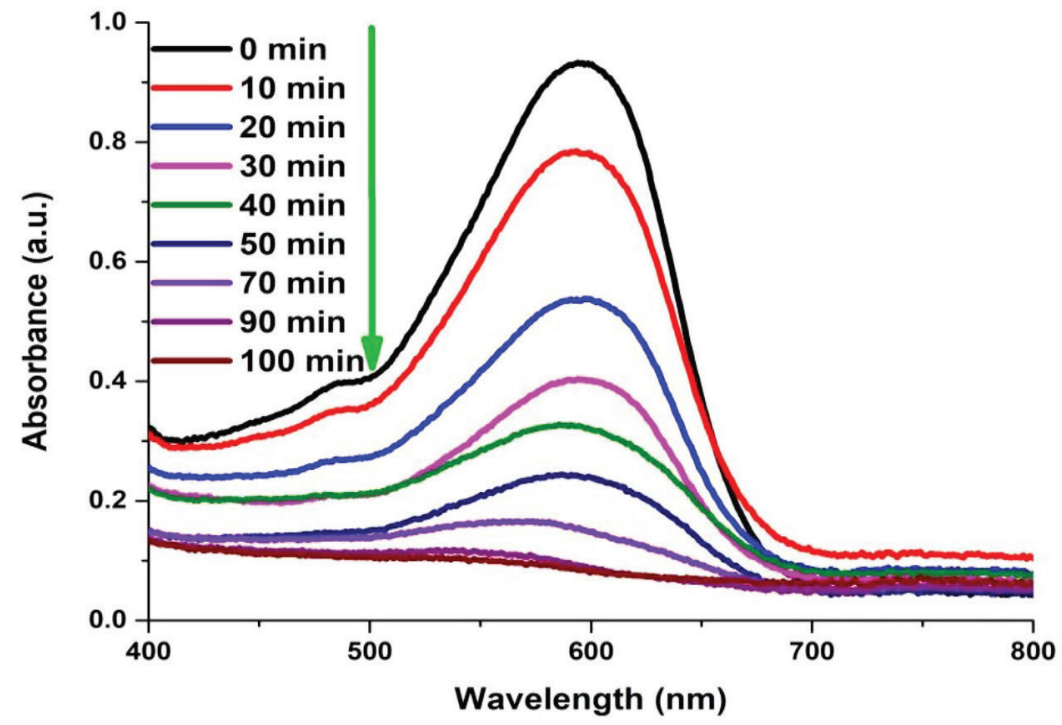

Fig. 9 - Time-dependent UV-Vis spectrum of RB5 aqueous solution (45 ppm) in presence of $\mathrm{H}_{2} \mathrm{O}_{2}(17.6 \mathrm{mM})$ and catalyst $\left(0.8 \mathrm{~g} \mathrm{~L}^{-1}\right)$ at $35 \pm 1{ }^{\circ} \mathrm{C}$

The reason for this being that, with the rise in temperature, oxidation proceeds at a faster rate ${ }^{43}$. This increase in oxidation could be attributed to the high heat energy which enhanced the collision between $\mathrm{H}_{2} \mathrm{O}_{2}$ and active sites of $\mathrm{Cu}$ (II)-hybrid, thereby promoting the generation of $\cdot \mathrm{OH}$ radicals $^{44}$. These $\cdot \mathrm{OH}$ radicals collide with RB5 molecules, thereby oxidizing them. As more $\cdot \mathrm{OH}$ radicals are generated by high temperature, thus the dye is more degraded. However, we operated all the reactions at $35{ }^{\circ} \mathrm{C}$, as high temperature requires more energy and increased process cost. Thus, $35^{\circ} \mathrm{C}$ was chosen as best temperature for the degradation studies. In addition, at higher temperature $\left(45^{\circ} \mathrm{C}\right)$, the catalytic activity of hybrid was not affected, implying that no possible leaching or decomposition of the catalyst occurred in the reaction environment.

On the basis of above studies, the absorbance of RB5 dye solution with time at the best reaction conditions, i.e., $17.6 \mathrm{mM} \mathrm{H}_{2} \mathrm{O}_{2}$ concentration, $0.8 \mathrm{~g} \mathrm{~L}^{-1}$ catalyst concentration, and $35^{\circ} \mathrm{C}$ temperature is shown in Fig. 9. As seen from the figure, the absorbance of dye decreases with time which indicates decrease in dye concentration with time. The concentration of RB5 corresponding to particular absorbance was calculated through the calibration curve obtained by plotting absorbance versus known concentrations of dye, and is presented in Fig. S6 (Supplementary Information).

\section{Role of scavenger on dye degradation}

To support the proposed mechanism of RB5 degradation involving $\mathrm{OH}$ radicals, dye degradation process was performed in the presence of a strong hydroxyl radical scavenger, isopropyl alcohol. Batch reaction was performed as described pre- viously. However, in this case, $2.5 \mathrm{~mL}$ of 2-propanol $(0.1 \mathrm{M})$ was also added to the reaction mixture. Effect of scavenger on dye degradation with time is presented in Fig. S7 (Supplementary Information). It was observed that dye degradation decreased from $91 \%$ (without scavenger) to $68 \%$ (in the presence of scavenger), thereby confirming the hydroxyl radicals as the active species during dye degradation process.

\section{Kinetic analysis}

On the basis of experimental analysis and reported literature ${ }^{45}$, it is proposed that the degradation reaction of RB5 with hydrogen peroxide $\left(\mathrm{H}_{2} \mathrm{O}_{2}\right)$ in presence of hybrid catalyst follows the following stoichiometric representation:

$$
\mathrm{RB} 5+\mathrm{H}_{2} \mathrm{O}_{2} \rightarrow \mathrm{P}+\mathrm{CO}_{2}
$$

where $\mathrm{P}$ symbolizes oxidized products after RB5 degradation. The other product formed during the degradation reaction was carbon dioxide. To obtain the kinetics of the reaction, concentration/absorbance of RB5 was monitored; however, the formation of carbon dioxide during the process was confirmed by lime water test, which supported the above proposed mechanism.

On the basis of kinetic analysis, the proposed rate of disappearance of RB5 is given below:

$$
\left(-r_{\mathrm{RB} 5}\right)=k\left(C_{\mathrm{RB} 5}\right)\left(C_{\mathrm{H}_{2} \mathrm{O}_{2}}\right)
$$

where, $C_{\mathrm{RB} 5}$ is concentration of RB5, and $C_{\mathrm{H}_{2} \mathrm{O}_{2}}$ is that of $\mathrm{H}_{2} \mathrm{O}_{2}$.

Further, to verify the proposed kinetics and evaluate the rate constant in Eq. 7, experiments were performed with best concentration of $\mathrm{H}_{2} \mathrm{O}_{2}$ 
(17.6 mM) for maximum degradation of RB5. The results were plotted to obtain the best fitted curve, and it was observed that the reaction followed pseudo-first order kinetics. Since the best concentration of $\mathrm{H}_{2} \mathrm{O}_{2}$ during the experiment was in excess, its concentration was nearly constant during the reaction. The resulting reaction kinetics is given below:

$$
\left(-r_{\mathrm{RB} 5}\right)=k_{\mathrm{obs}}\left(C_{\mathrm{RB} 5}\right)
$$

where, $k_{\text {obsk }}=k\left(C_{\mathrm{H}_{2} \mathrm{O}_{2}}\right)$.

In the above equation, $k_{\mathrm{obs}}$ is pseudo first order rate constant, and $k$ is the rate constant of the actual second order reaction. The system used in this investigation is a liquid-liquid system, thus, the volume of the reaction mixture was considered as constant. For this system, following correlation represents the relationship between RB5 concentration and time:

$$
-\ln \left[\left(C_{\mathrm{RB} 5}\right)_{t} /\left(C_{\mathrm{RB} 5}\right)_{0}\right]=k_{\mathrm{obs}} \cdot t
$$

where, $\left(C_{\mathrm{RB} 5}\right)_{0}$ and $\left(C_{\mathrm{RBS} 5}\right)_{t}$ are the initial concentration and time-dependent concentration of RB5, respectively. To further verify the kinetics, $-\ln \left[\left(C_{\mathrm{RB} S}\right) /\right.$ $\left.\left(C_{\mathrm{RB} 5}\right)_{0}\right]=k_{\mathrm{obs}} \cdot t$ obtained at $35^{\circ} \mathrm{C}$ was plotted against time $(t)$, as shown in Fig. S8 (Supplementary Information); the plotted data points lie on straight line with regression coefficient $R^{2}$ value equal to 0.993 .

This confirmed that the reaction was of pseudo first-order and the observed value of the rate constant $\left(k_{\text {obs }}\right)$ was $0.026 \mathrm{~min}^{-1}$. In addition, average calculated value of the second order reaction rate constant $(k)$ was $1.42 \mathrm{~L} \mathrm{~mol}^{-1} \mathrm{~min}^{-1}$ at $35^{\circ} \mathrm{C}$.

$$
\mathrm{C}_{26} \mathrm{H}_{21} \mathrm{~N}_{5} \mathrm{Na}_{4} \mathrm{O}_{19} \mathrm{~S}_{6}+\cdot \mathrm{OH}
$$
(RB5)

\section{Oxidation of organic substrates}

Conditions for oxidizing organic substrates (tetralin, cyclohexane, cyclohexanol and cyclopentanol) were optimized in terms of various solvents (viz., glacial acetic acid, dimethyl sulfoxide, dimethylformamide, and acetonitrile) and temperature variation $(40,50,60$, and 70$){ }^{\circ} \mathrm{C}\left( \pm 1{ }^{\circ} \mathrm{C}\right)$ at 17.6 $\mathrm{mM} \mathrm{H} \mathrm{O}_{2}$ and $0.02 \mathrm{~g}$ catalyst. Tetralin was taken as reference substrate. It was observed that maximum product yield was obtained in case of acetonitrile as compared to other solvents. Previous studies have also shown that acetonitrile is an effective and widely used solvent ${ }^{7,46}$. We also observed in our previous work ${ }^{47}$ that acetonitrile was the best solvent in tetralin oxidation by polyoxometalate based catalyst. Therefore, other experiments were performed using acetonitrile as solvent. While observ-
Experiments were also conducted at two more temperatures, i.e., $45^{\circ} \mathrm{C}$ and $55^{\circ} \mathrm{C}$ to obtain the activation energy of the reaction. $-\ln \left[\left(C_{\mathrm{RB} 5}\right)_{t} /\left(C_{\mathrm{RB} 5}\right)_{0}\right]$ vs time graph at these temperatures show same trend as obtained at $35^{\circ} \mathrm{C}$. The rate constants at two aforementioned temperatures were $1.54 \mathrm{~L} \mathrm{~mol}^{-1} \mathrm{~min}^{-1}$ and $1.59 \mathrm{~L} \mathrm{~mol}^{-1} \mathrm{~min}^{-1}$, respectively. In addition, the calculated values of frequency factor and activation energy of the reactions were 8.73 and $4632 \mathrm{~J} \mathrm{~mol}^{-1}$ $\mathrm{K}^{-1}$. The final rate expression for degradation of $\mathrm{RB} 5$ is as follows:

$$
\left(-r_{\mathrm{RB} 5}\right)=8.73 e^{-\frac{4632}{R T}} C_{\mathrm{RB} 5} C_{\mathrm{H}_{2} \mathrm{O}_{2}}
$$

$-\ln \left[\left(C_{\mathrm{RB} 5}\right)_{t} /\left(C_{\mathrm{RB} 5}\right)_{0}\right]$ vs time graph (at $35{ }^{\circ} \mathrm{C}$ ) was also plotted for different concentrations of $\mathrm{H}_{2} \mathrm{O}_{2}$ and catalyst, and it followed the same trend as obtained in Fig. S8 (Supplementary Information).

\section{Plausible mechanism for RB5 degradation}

The mechanism suggests that $\mathrm{H}_{2} \mathrm{O}_{2}$ molecules are firstly activated by the $\mathrm{Cu}$ (II) catalyst to generate highly active $\cdot \mathrm{OH}$ radicals. The hydroxyl radicals have the capability of attacking organic substrates, resulting in the chemical decomposition of these substrates by $\mathrm{H}$ abstraction and addition to $\mathrm{C}=\mathrm{C}$ unsaturated bonds ${ }^{41}$. Thus, the generated $\cdot \mathrm{OH}$ radicals combined with $\mathrm{RB} 5$, and converted it into dye-radical adduct. This intermediate product later on converted into oxidized products ${ }^{45}$ and carbon dioxide. The mechanism for the degradation of RB5 is shown in eq. 11 .

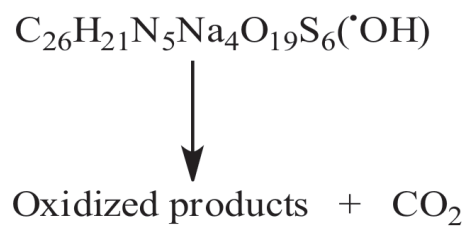

ing temperature variation effect, it was noted that maximum yield was obtained at $70{ }^{\circ} \mathrm{C}\left( \pm 1{ }^{\circ} \mathrm{C}\right)$. Thus, the catalytic ability of the synthesized catalyst was evaluated through oxidation of all organic substrates in acetonitrile at $70{ }^{\circ} \mathrm{C}\left( \pm 1{ }^{\circ} \mathrm{C}\right)$ with 0.02 g catalyst; keeping $\mathrm{H}_{2} \mathrm{O}_{2}$ concentration at $17.6 \mathrm{mM}$. The oxidation products obtained after catalyzing aforementioned organic substrates at best reaction conditions were analyzed by GC-MS, and the graphs thus obtained are shown in Fig. S9-S16 (Supplementary Information). The results obtained by the oxidation of these organic substrates after 4 $\mathrm{h}$ are summarized in Table 1 . The results show that organic substrates were readily oxidized into their respective products with good yield, and good selectivity was obtained for the value added industrial products. 
Table 1 Oxidation of cycloalkanes and cycloalcohols with $\mathrm{H}_{2} \mathrm{O}_{2}$ catalyzed by hybrid catalyst

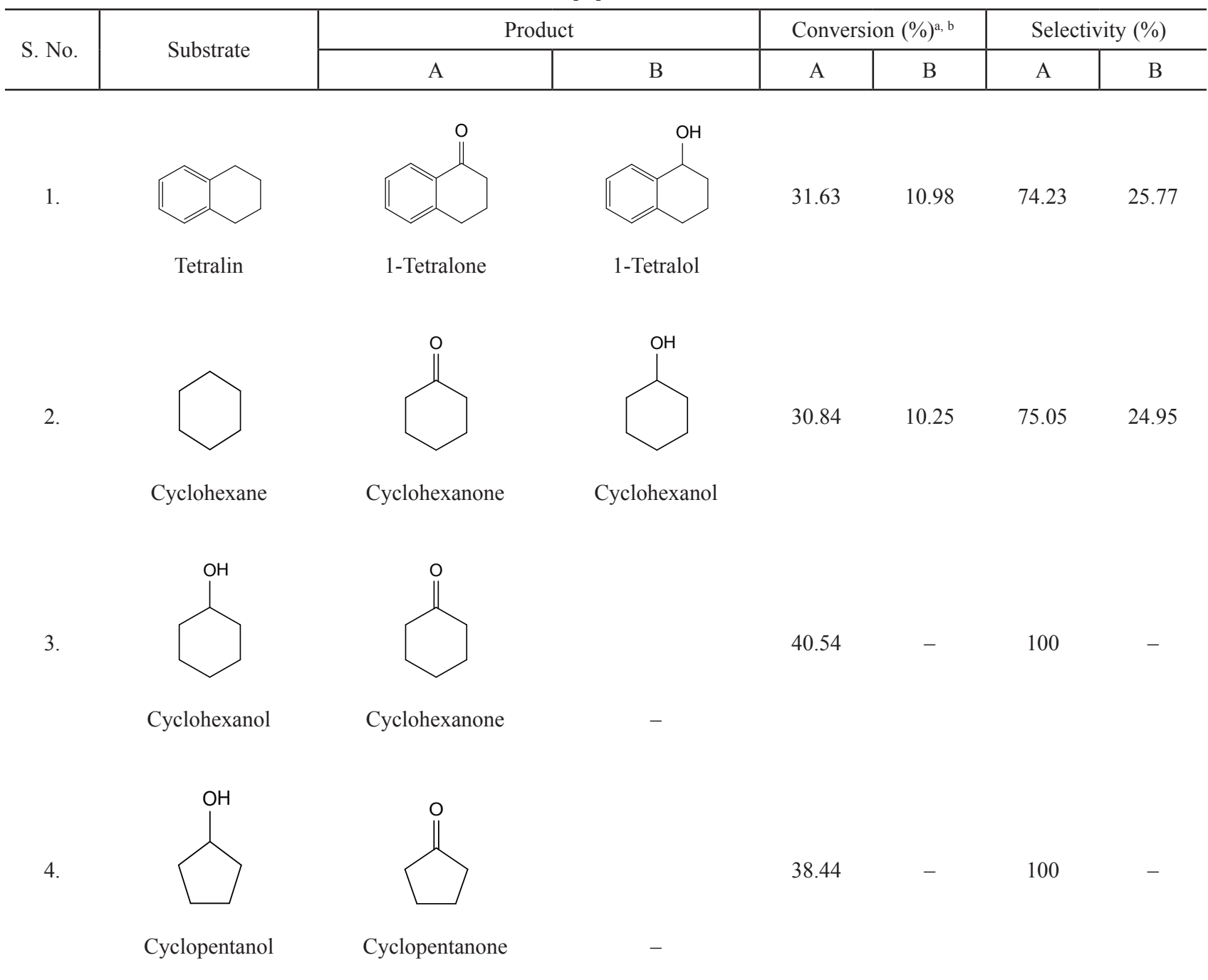

(A) Ketone

(B) Alcohol

(a) Reaction conditions: Substrate $(5 \mathrm{mM}), \mathrm{H}_{2} \mathrm{O}_{2}(17.6 \mathrm{mM})$, catalyst $(0.02 \mathrm{~g}), \mathrm{CH}_{3} \mathrm{CN}$ (solvent), $T=70{ }^{\circ} \mathrm{C}\left( \pm 1{ }^{\circ} \mathrm{C}\right)$

(b) Determined from GC analysis

Blank catalytic experiment, i.e., without catalyst, was also conducted for tetralin oxidation at the best reaction conditions, but negligible product yield was obtained. This showed the importance of synthesized catalyst in these conversions.

Among all the tested substrates, tetralin gave the highest percent conversion of $42.61 \%$ into 1 -tetralone (31.63\% yield) and 1-tetralol (10.98\% yield) with the selectivity of $74.23 \%$ and $25.77 \%$ for tetralone and tetralol, respectively. Cyclohexane showed the percent conversion of $41.09 \%$ into cyclohexanone (30.84\% yield) and cyclohexanol $(10.25 \%$ yield) with the selectivity of $75.05 \%$ and $24.95 \%$, respectively. Cyclohexanol gave the product (cyclohexanone) yield of $40.54 \%$ with $100 \%$ selectivity, and cyclopentanol gave the product (cyclopentanone) yield of $38.44 \%$ with $100 \%$ selectivity. Oxidation products obtained are of high in- dustrial value. The advantage of using heterogeneous catalysts is their recyclability and simple workup process, which may lead to future industrial development process.

\section{Reusability and stability of the catalyst}

The reusability of the catalyst was tested for dye degradation and oxidation of tetralin. It was observed from the results that there was no substantial loss in the catalytic efficiency of the $\mathrm{Cu}$ (II)-hybrid. Percentage degradation of dye was $90.84 \%$ and $90.35 \%$ in the second and third catalytic cycle, respectively; slightly lower than first catalytic cycle, which gave $90.99 \%$ dye degradation percentage.

The GC-MS graphs obtained for second and third catalytic cycle in the oxidation of tetralin are shown in Fig. S17-S20 (Supplementary Informa- 


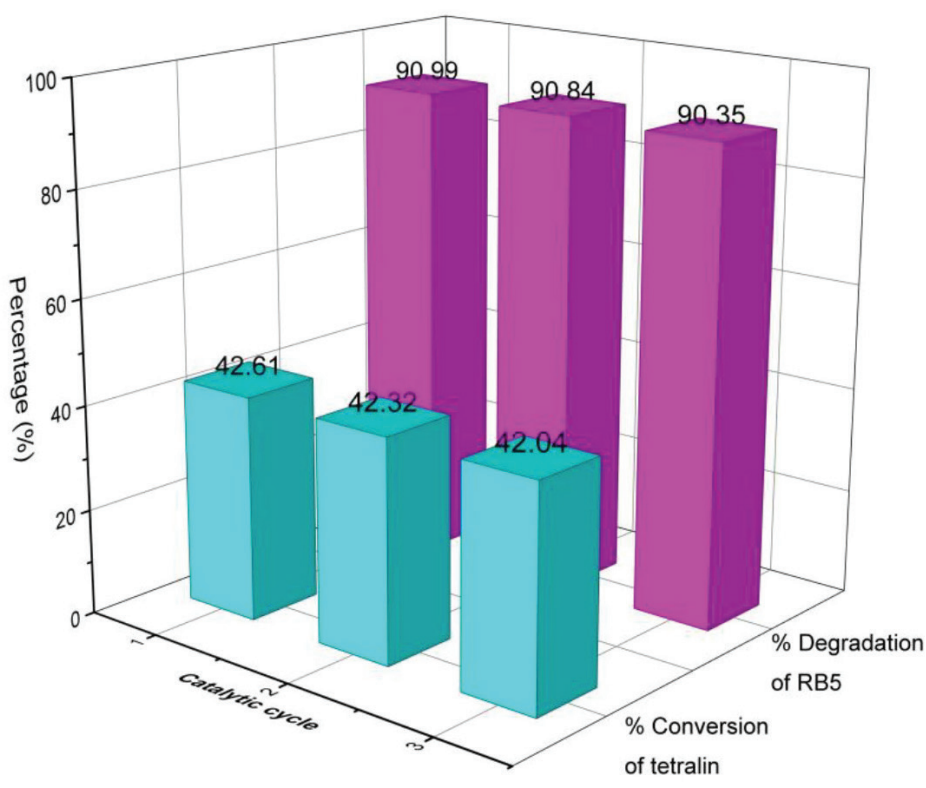

Fig. 10 - Catalytic reusability of $\mathrm{SiO}_{2}{ }^{*} \mathrm{NH}_{2}{ }^{*} \mathrm{DPPD}{ }^{*} \mathrm{Cu}$

tion). These results indicated that in the second and third catalytic cycle, there was no significant loss in the product yield of organic substrates. Conversion of tetralin was $42.32 \%$ and $42.04 \%$ in the second and third catalytic cycle, respectively, with the product selectivity of $74.64 \%$ (tetralone) and 25.36 $\%$ (tetralol) in the second run, and $73.59 \%$ (tetralone) and $26.41 \%$ (tetralol) in the third run. The graphic representation for reusability of the catalyst for dye degradation and substrate conversion in its first, second, and third cycle is presented in Fig. 10.

Leaching experiment was also performed to observe the stability of hybrid material. The results obtained from the leaching experiments showed that there was no significant increase in degradation when catalyst was filtered from the reaction mixture after 30 minutes and filtrate (obtained during leaching experiment) was allowed to react for another 60 minutes. Time-dependent UV-Vis spectrum of RB5 aqueous solution for observing leaching of the metal ion from the hybrid material is shown in Fig. S21 (Supplementary Information). Previous studies have shown that $\mathrm{Cu}$ (II) ions have the tendency to degrade dyes $^{48,49}$, and hence, in our case, dye would have been degraded if leaching of metal ion had occurred. This supports that no substantial leaching of metal ions had occurred, and thereby corroborates that the synthesized catalyst was truly heterogeneous in nature. To observe the stability of the synthesized hybrid material, FT-IR and SEM analyses of reused hybrid were also performed. Surface morphologies of fresh and used catalyst were found almost the same, as seen in SEM images, Fig. S22 (Supplementary Information). Only some aggregation was observed on the surface of used catalyst.
FTIR spectra of fresh and recovered catalyst revealed no obvious change in the pattern, Fig. S23 (Supplementary Information). Thus, it can be concluded that $\mathrm{Cu}(\mathrm{II})$-hybrid had not degraded during experiments.

\section{Conclusions}

Silica surface was modified with 3-(2-aminoethylamino) propyltrimethoxysilane and successfully reacted with 1,3-diphenyl-1,3-propanedione to yield Schiff's base. Copper(II) ion was then immobilized on the Schiff's base-modified silica gel, thereby synthesizing a novel $\mathrm{Cu}(\mathrm{II})$-based inorganic-organic hybrid by following facile synthetic method. The hybrid was characterized by relevant spectral and surface analytical techniques, and used as an efficient heterogeneous catalyst for oxidative degradation of reactive black 5 dye with $91 \%$ degradation and oxidation of some organic substrates, viz., tetralin, cyclohexane, cyclohexanol and cyclopentanol to obtain products of industrial importance. Conversion of tetralin, cyclohexane, cyclohexanol and cyclopentanol was $42.61 \%, 41.09 \%$, $40.54 \%$ and $38.44 \%$, respectively. Reaction kinetics for dye degradation was studied in detail, and was found to follow second order kinetics with rate constant equal to $1.42 \mathrm{~L} \mathrm{~mol}^{-1} \mathrm{~min}^{-1}$ at $35{ }^{\circ} \mathrm{C}$. Frequency factor and activation energy of the reaction were also calculated as 8.73 and $4632 \mathrm{~J} \mathrm{~mol}^{-1} \mathrm{~K}^{-1}$, respectively. The catalytic activities were studied in mild reaction conditions for an eco-friendly, green approach. Catalyst was easily recovered by filtration and washing, and used three times with almost no significant loss in its catalytic activity.

\section{ACKNOWLEDGMENTS}

$A N$, one of the authors, is thankful to the University Grant Commission (UGC), New Delhi, India, for awarding Junior Research Fellowship. The authors are grateful to Centre for Interdisciplinary Research (CIR), MNNIT, Allahabad for carrying out UV-Vis spectroscopic and powder-XRD analyses. All authors also thank the Director, MNNIT for providing basic facilities. The authors are deeply grateful to Malaviya National Institute of Technology, Jaipur, for performing FTIR and TGA, IIT Kanpur for SEM, and Indian Institute of Science (IISc), Bangalore, for recording the ${ }^{13} \mathrm{C} N M R$ spectra. We would also like to thank SAIF, IIT Bombay, for ICPAES, Central Instrumentation Laboratory, Panjab University for GC-MS, and Aligarh Muslim University for EPR analysis. 
Supplementary Information

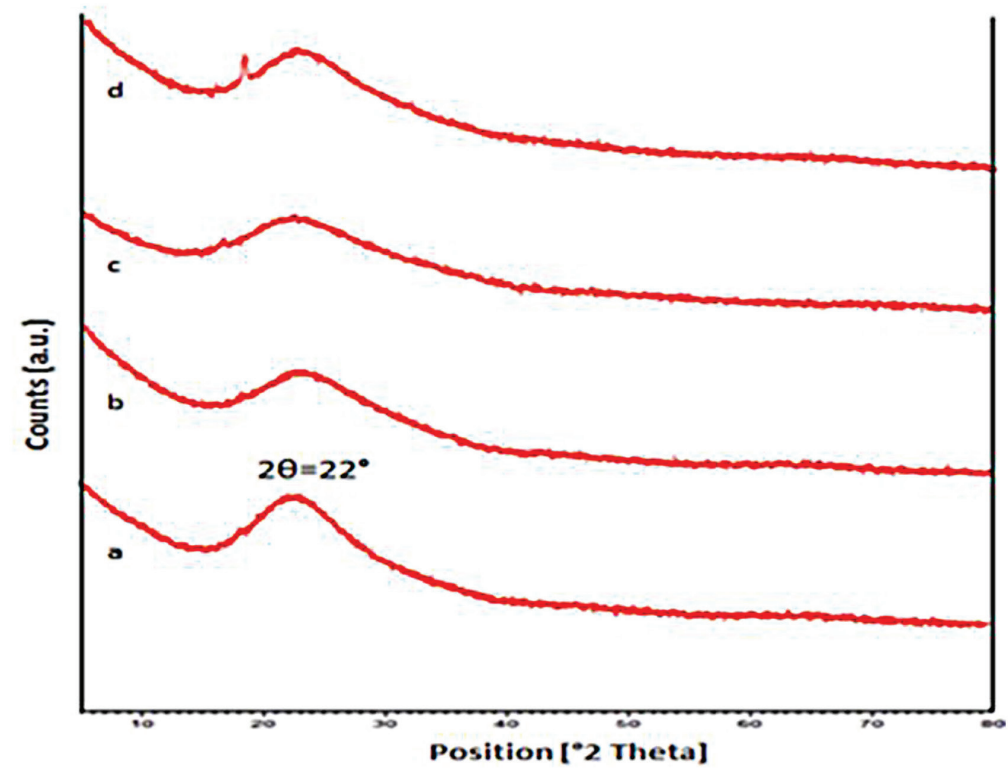

Fig. S 1 - Powder XRD patterns of (a) $\mathrm{SiO}_{2}$ gel, (b) $\mathrm{SiO}_{2} * \mathrm{NH}_{2}$, (c) $\mathrm{SiO}_{2}{ }^{*} \mathrm{NH}_{2}{ }^{*} \mathrm{DPPD}$, (d) $\mathrm{SiO}_{2}{ }^{*} \mathrm{NH}_{2}{ }^{*} \mathrm{DPPD}{ }^{*} \mathrm{Cu}$
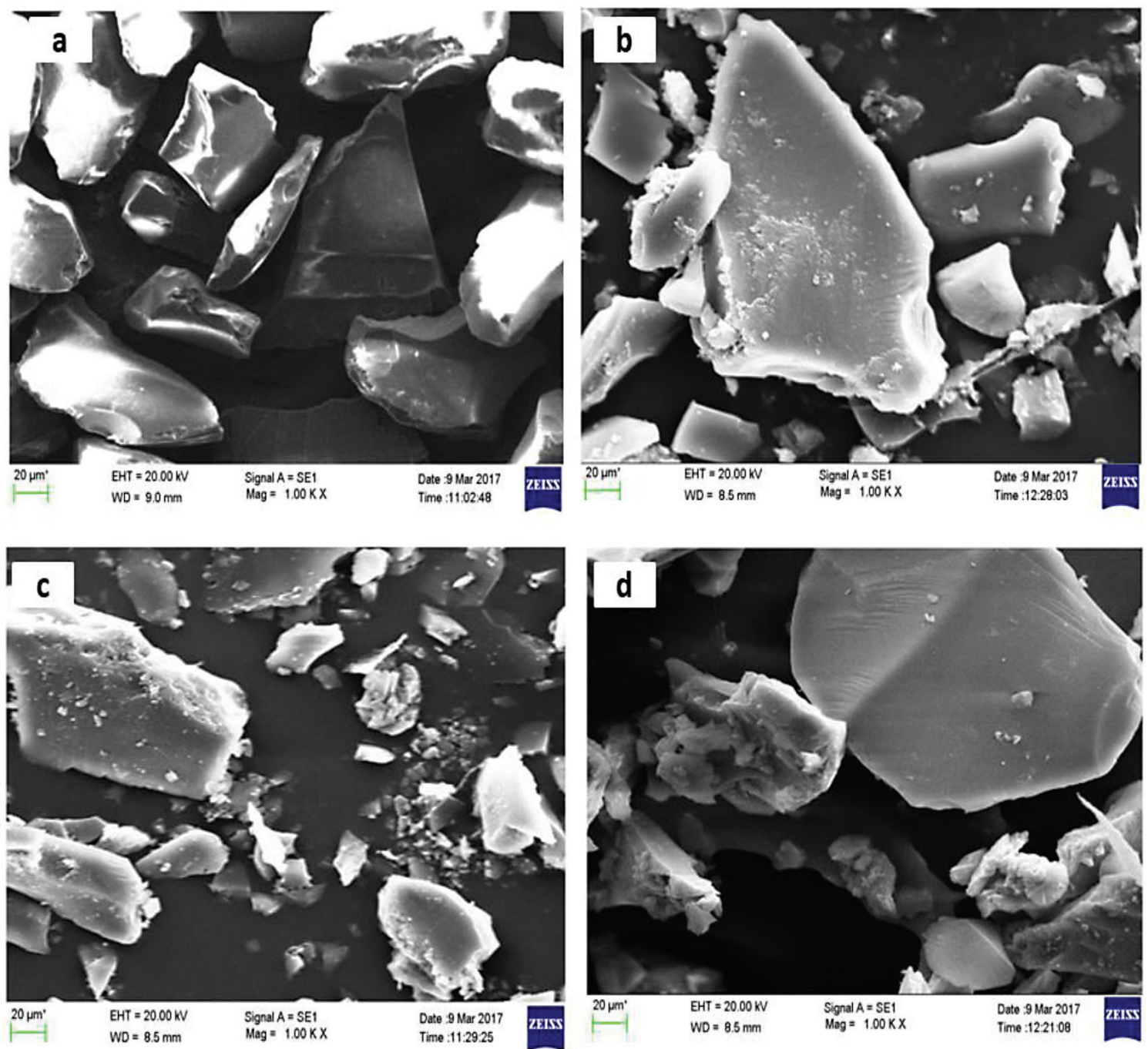

Fig. S 2 - SEM images of (a) $\mathrm{SiO}_{2}$ gel, (b) $\mathrm{SiO}_{2}{ }^{*} \mathrm{NH}_{2}$, (c) $\mathrm{SiO}_{2}{ }^{*} \mathrm{NH}_{2}{ }^{*} \mathrm{DPPD}$, (d) $\mathrm{SiO}_{2}{ }^{*} \mathrm{NH}_{2}{ }^{*} \mathrm{DPPD}{ }^{*} \mathrm{Cu}$ 


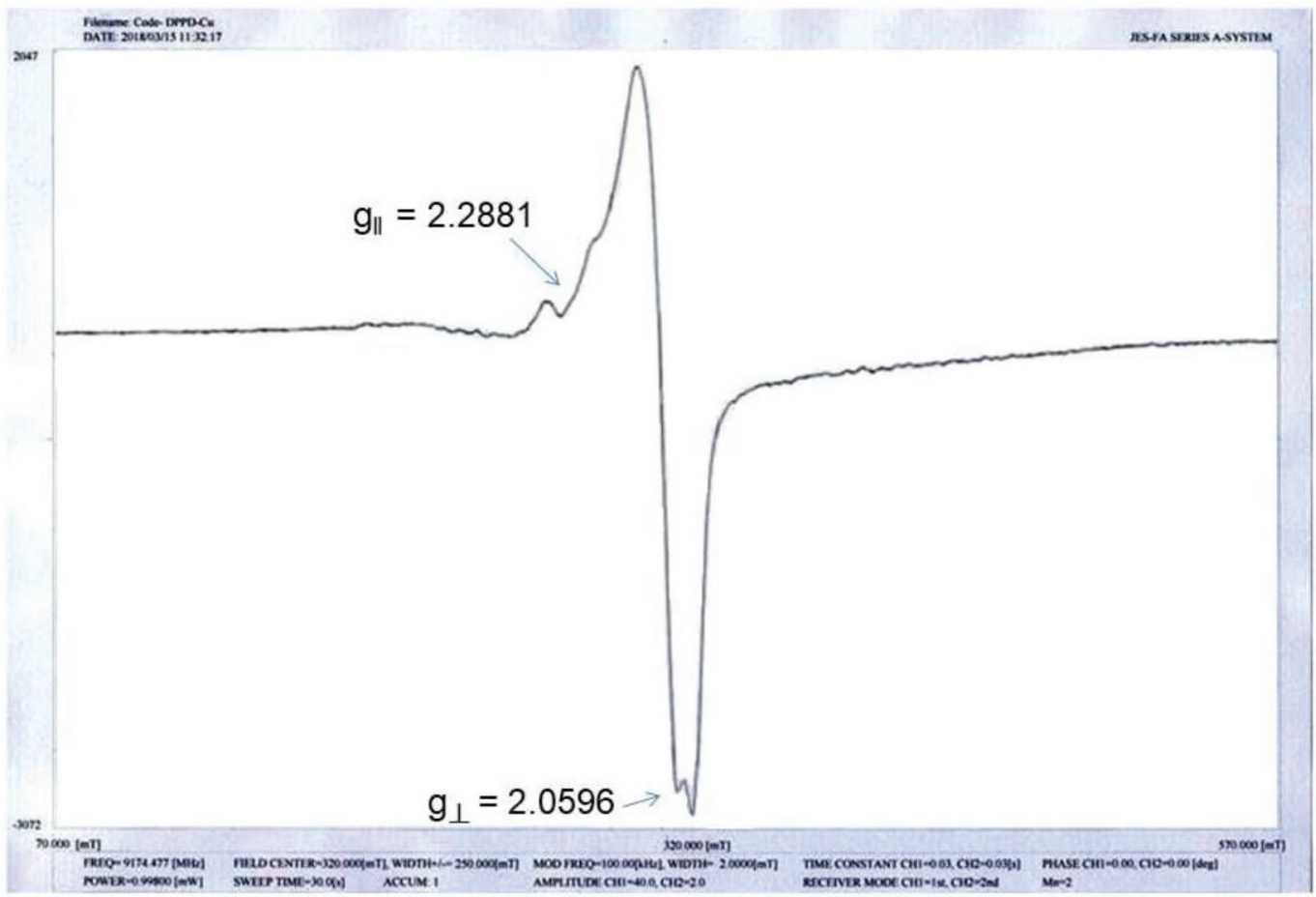

Fig. S3 - X-band EPR spectrum of $\mathrm{SiO}_{2}{ }^{*} \mathrm{NH}_{2}{ }^{*} D P P D * C u$

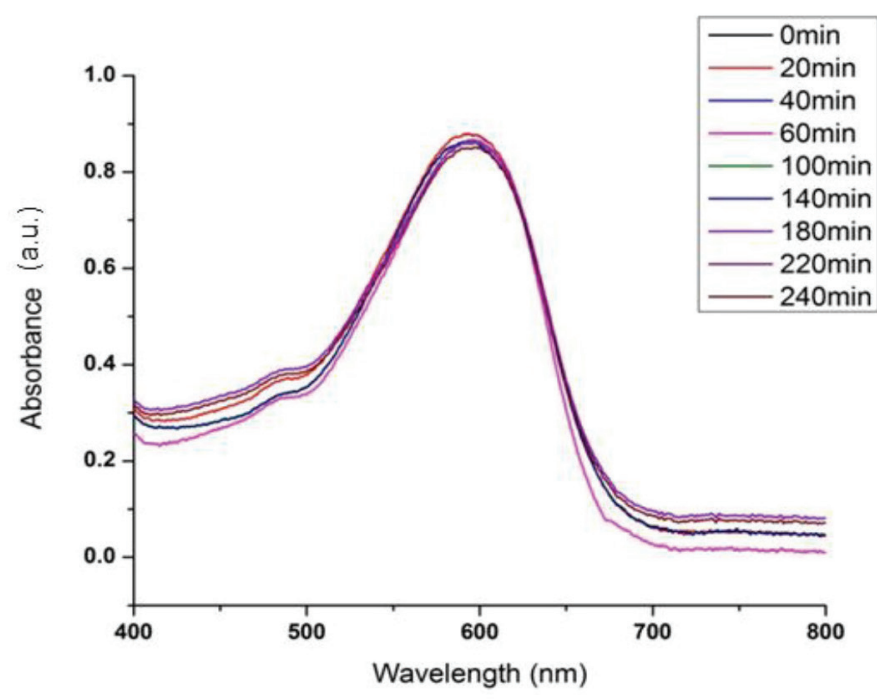

Fig. S 4 - Time-dependent UV-Vis spectrum of RB5 aqueous solution in presence of catalyst only (4 hours study)

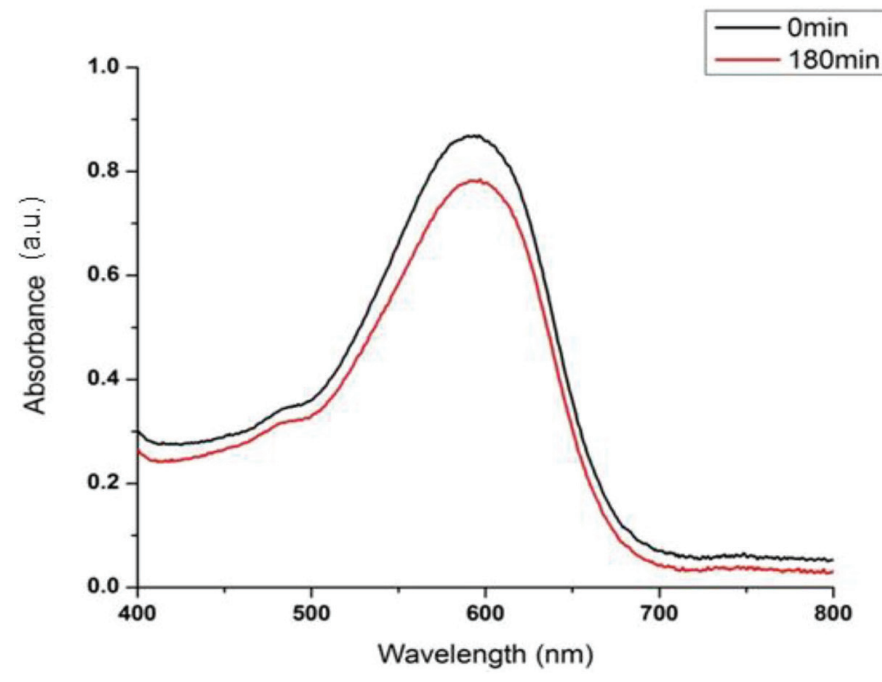

Fig. S 5 - Time-dependent UV-Vis spectrum of RB5 aqueous solution in presence of silica gel and $\mathrm{H}_{2} \mathrm{O}_{2}(17.6$ $m M)$, instead of catalyst 


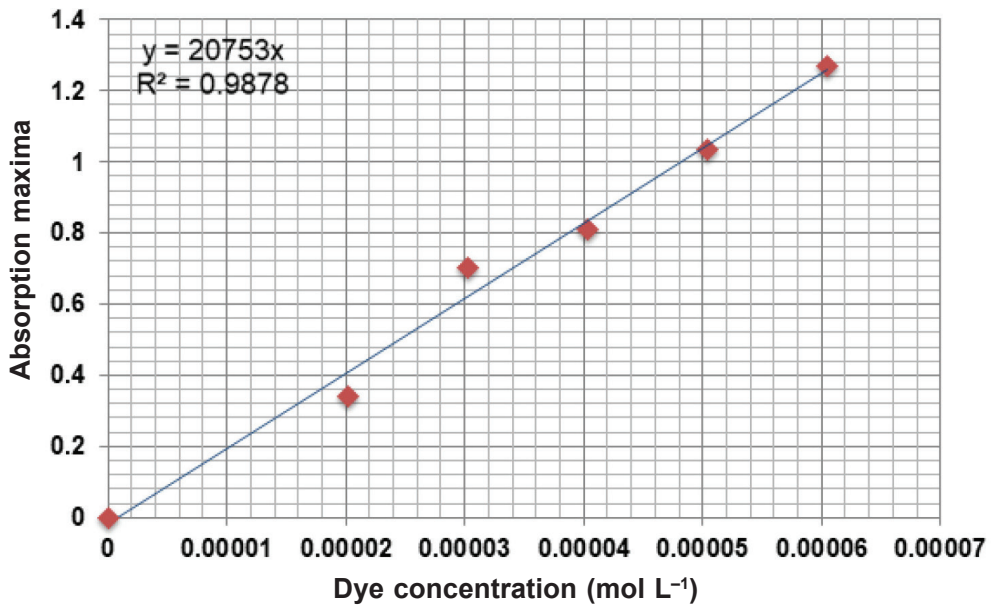

Fig. S 6 - Calibration curve-absorbance versus concentration of RB5

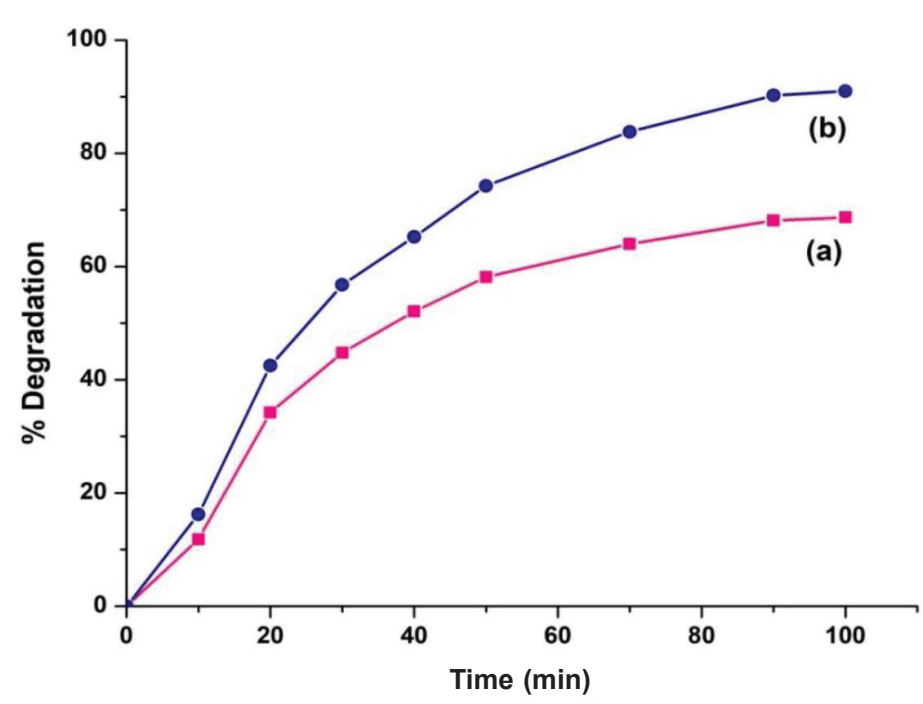

Fig. S 7 - Degradation of RB5 in (a) presence of scavenger, and (b) absence of scavenger (RB5 concentration $=45 \mathrm{ppm}, \mathrm{H}_{2} \mathrm{O}_{2}$ concentration $=17.6 \mathrm{mM}$, catalyst concentration $=0.8 \mathrm{~g} \mathrm{~L}^{-I^{2}}$, Scavenger concentration $=0.1 \mathrm{M}, \mathrm{T}=35 \pm 1{ }^{\circ} \mathrm{C}$ )

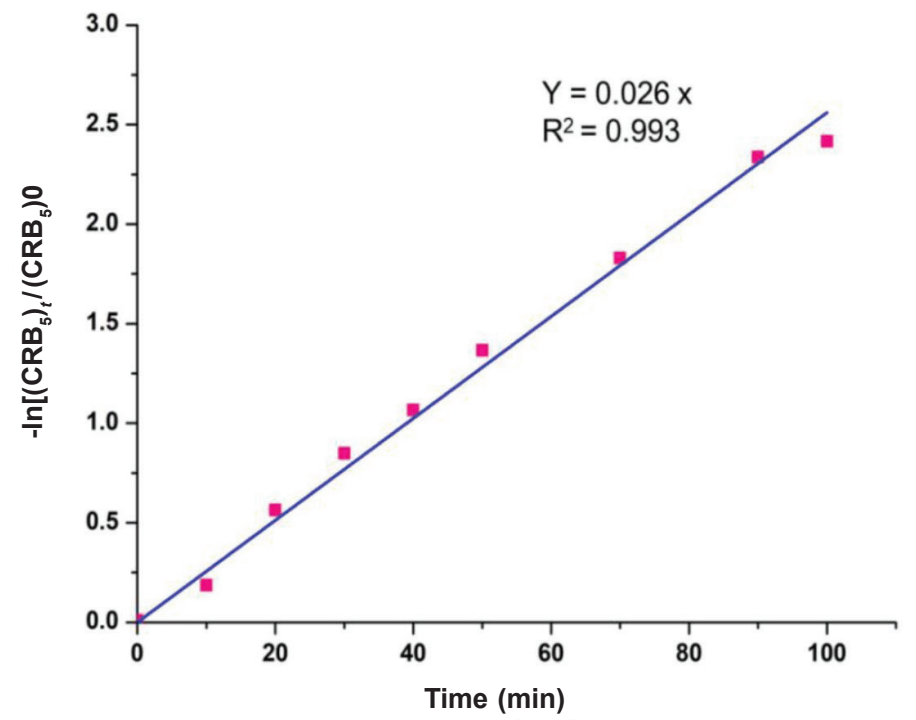

Fig. S 8 - First order plot of $-\ln \left[\left(C_{R B}\right)_{t} /\left(C_{R B S}\right)_{0}\right]$ versus time for degradation of $\mathrm{RB} 5$ (RB5 concentration $\stackrel{R B 5}{=} 45 \mathrm{ppm}, \mathrm{H}_{2} \mathrm{O}_{2}$ concentration $=17.6 \mathrm{mM}$, catalyst concentration $=0.8 \mathrm{~g} \mathrm{~L}^{-1}, T$ $=35 \pm 1{ }^{\circ} \mathrm{C}$ )

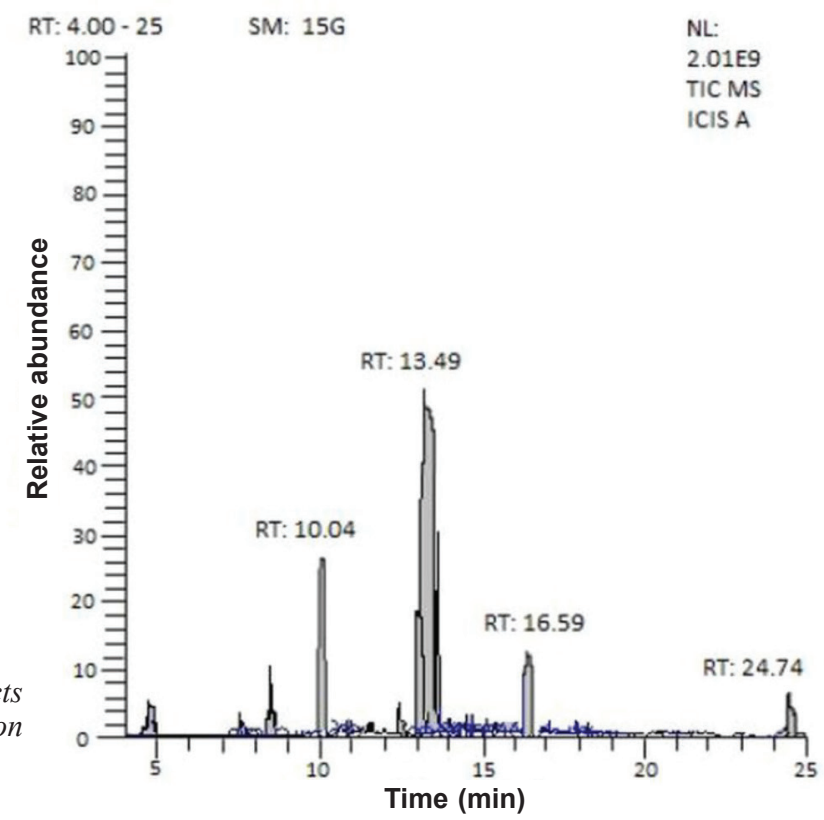

Fig. S $9-G C$ graph of products obtained by tetralin conversion 


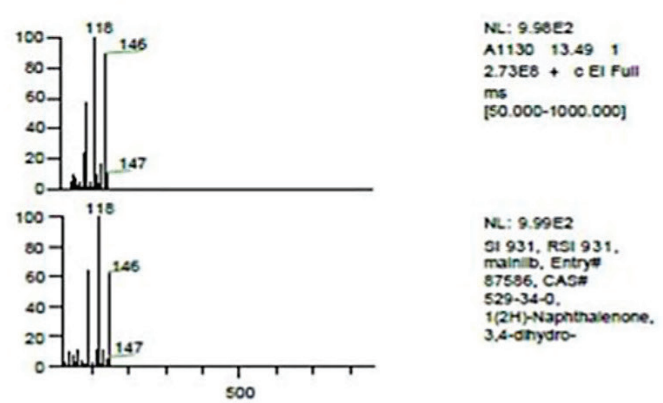

1(2H)-Naphthalenone 3.4-dihydro-

Formula C10H 100 . MW 14e. CAS\# 529-34-0. Entry 87586

à-Tetralone

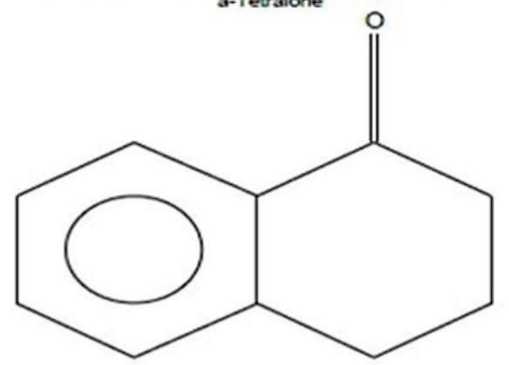

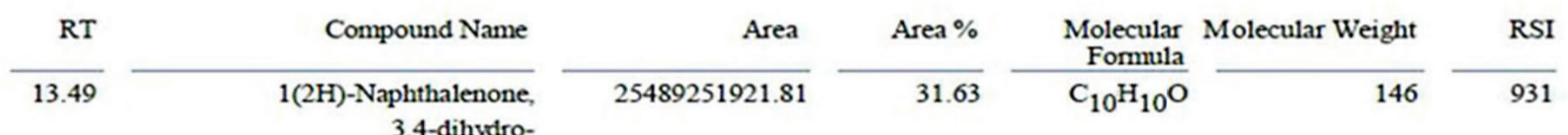

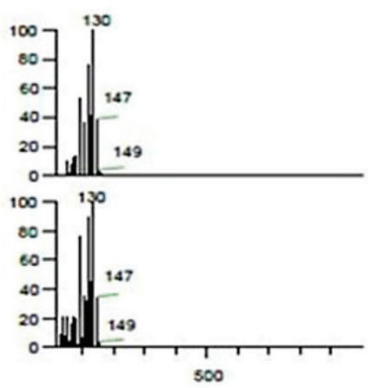

NL: $9.98 e^{2}$

1.38Es + O EI Fu

ms

1-Naphthalend, 1,2,3,4-tetrahydro-

Formula C1OH12O. MW 148, CASw 529-33-9. Entryll 102437

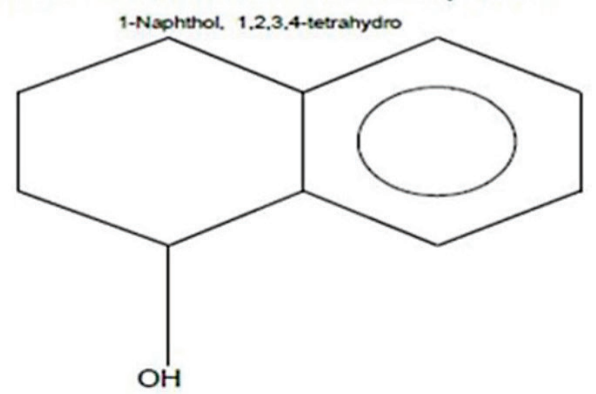

\begin{tabular}{|c|c|c|c|c|c|}
\hline RT & Compound Name & Area & Area \% & $\begin{array}{r}\text { Molecular } \\
\text { Formula }\end{array}$ & Molecular Weight \\
\hline 13.11 & $\begin{array}{r}\text { 1-Naphthalenol, } 1,2,3,4- \\
\text { tetrahydro- }\end{array}$ & 8848308128.40 & 10.98 & $\mathrm{C}_{10} \mathrm{H}_{12} \mathrm{O}$ & 148 \\
\hline
\end{tabular}

Fig. S $10-M S$ of products obtained by tetralin conversion

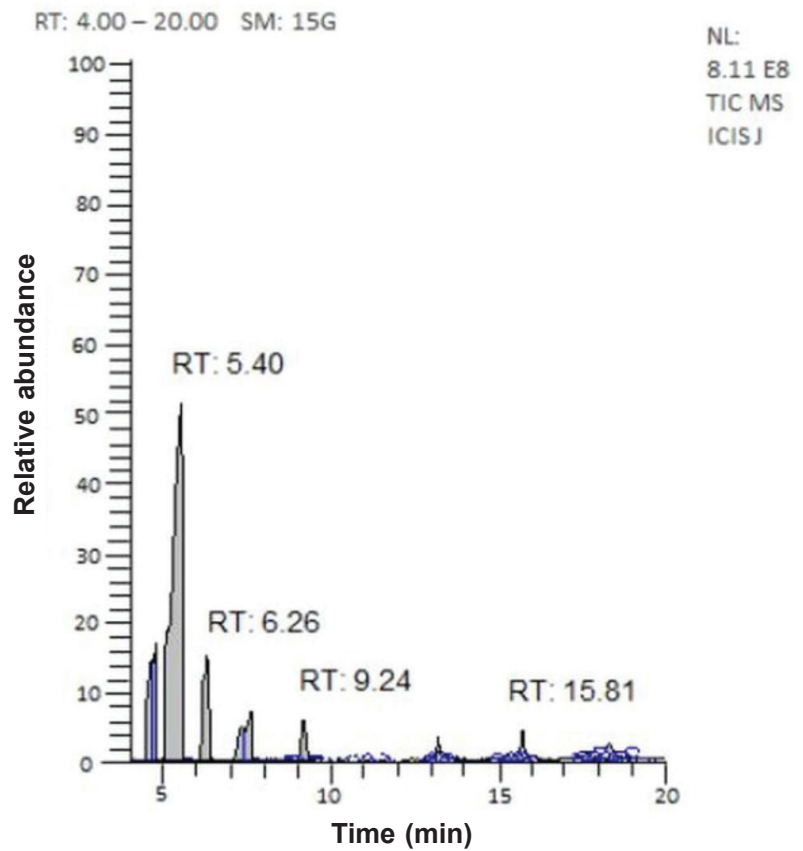

Fig. S $11-G C$ of products obtained by cyclohexane conversion 


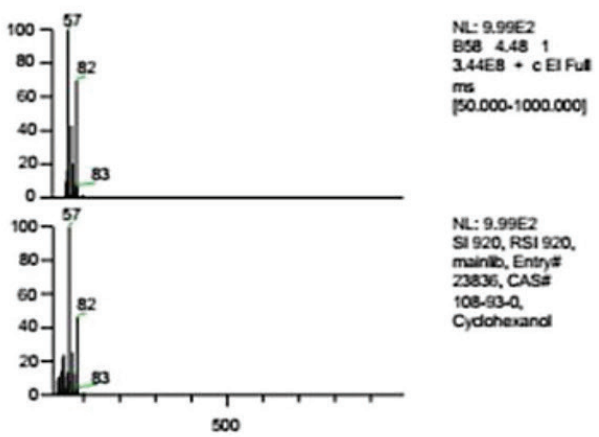

Cyclohexanol

Formula $\mathrm{C}_{6} \mathrm{H}_{12} \mathrm{O}$, MW 100, CAS\# 108-93-0, Entry\# 23836 Cyclohexyl alcohol ethyl-

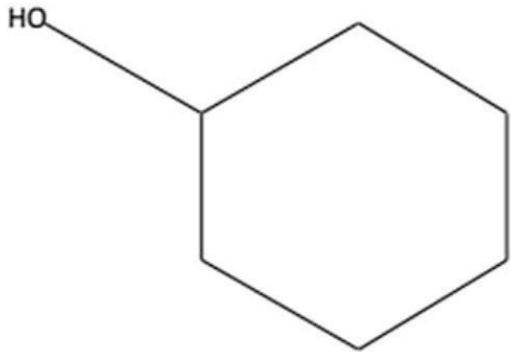

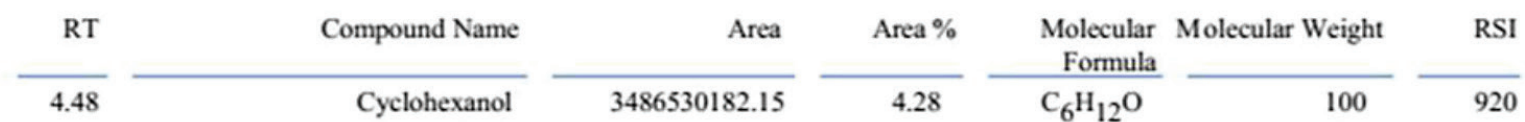
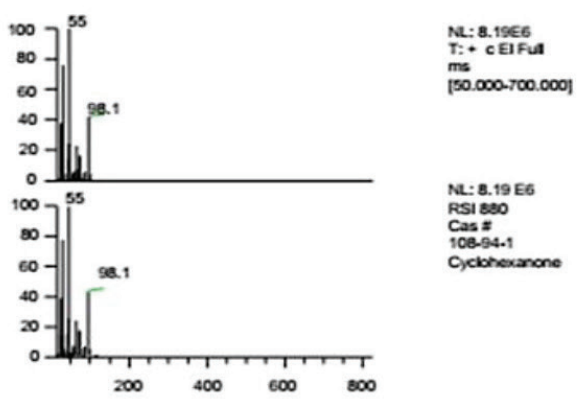

Cyclohexanone Formula $\mathrm{C}_{6} \mathrm{H}_{10} \mathrm{O}$. MW 98, CASU 108-94-1
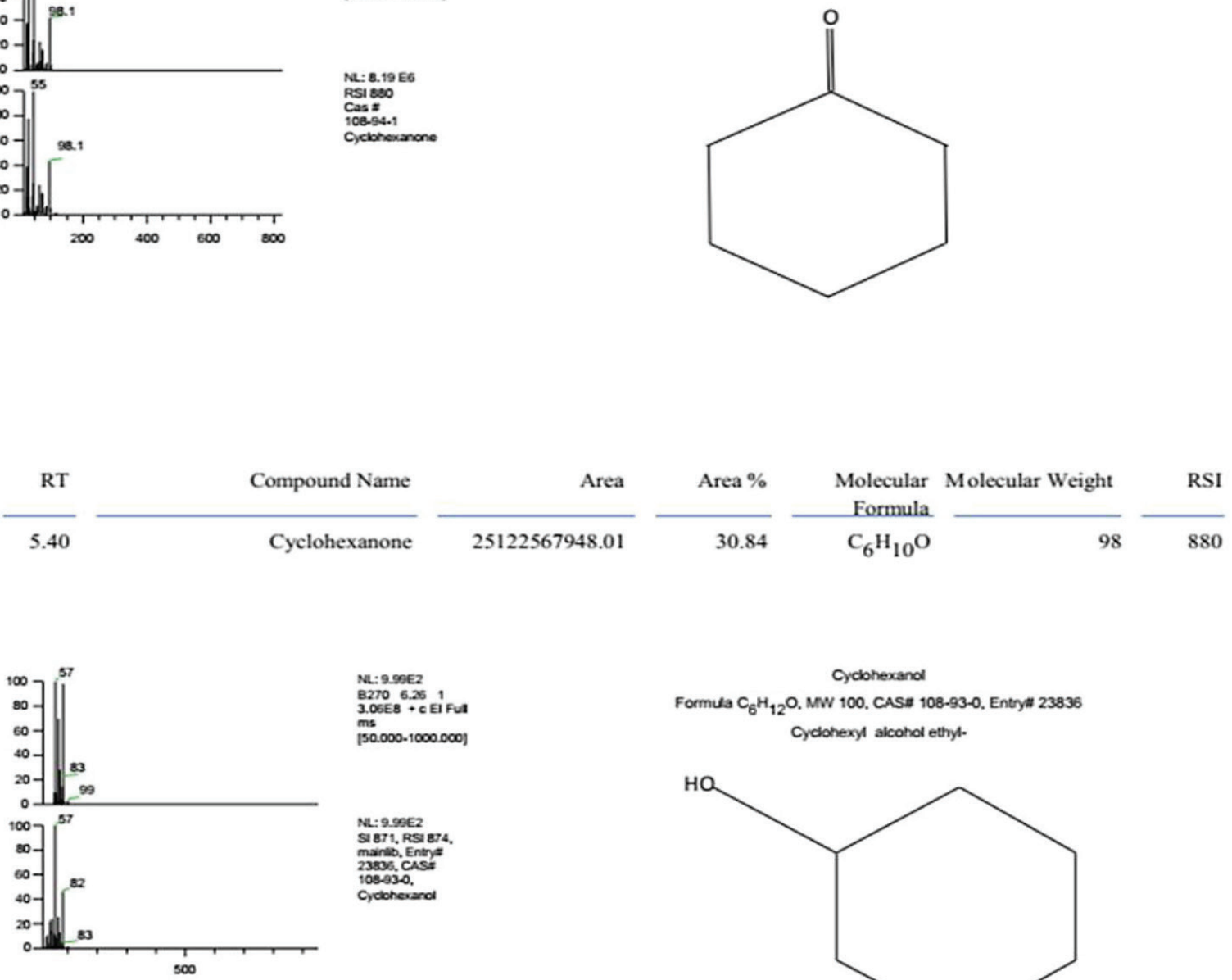

Cyclohexand

Formula $\mathrm{C}_{6} \mathrm{H}_{12} \mathrm{O}, \mathrm{MW} 100$, CASE 108-93-0. Entryll 23836 Cyclonexyl alcohol ethyt.

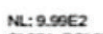

Sig71, RSI B

mantib, Entrya
$2380 \%$ CAse

103030

Cyobherand

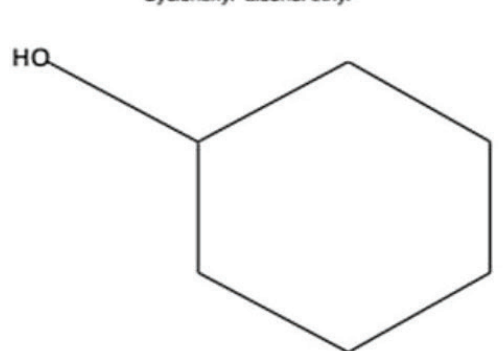

\begin{tabular}{|c|c|c|c|c|c|c|}
\hline RT & Compound Name & Area & Area $\%$ & $\begin{array}{r}\text { Molecular } \\
\text { Formula }\end{array}$ & Molecular Weight & RSI \\
\hline 6.26 & Cyclohexanol & 4863220838.18 & 5.97 & $\mathrm{C}_{6} \mathrm{H}_{12} \mathrm{O}$ & 100 & 874 \\
\hline
\end{tabular}

Fig. S $12-M S$ of products obtained by cyclohexane conversion 


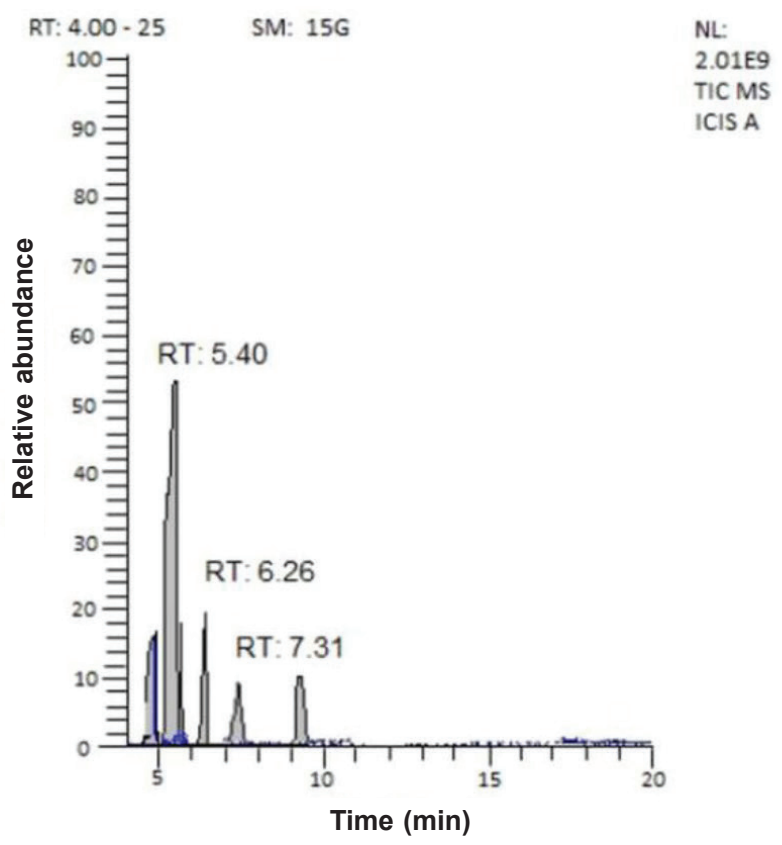

Fig. S13-GC of products obtained by cyclohexanol conversion
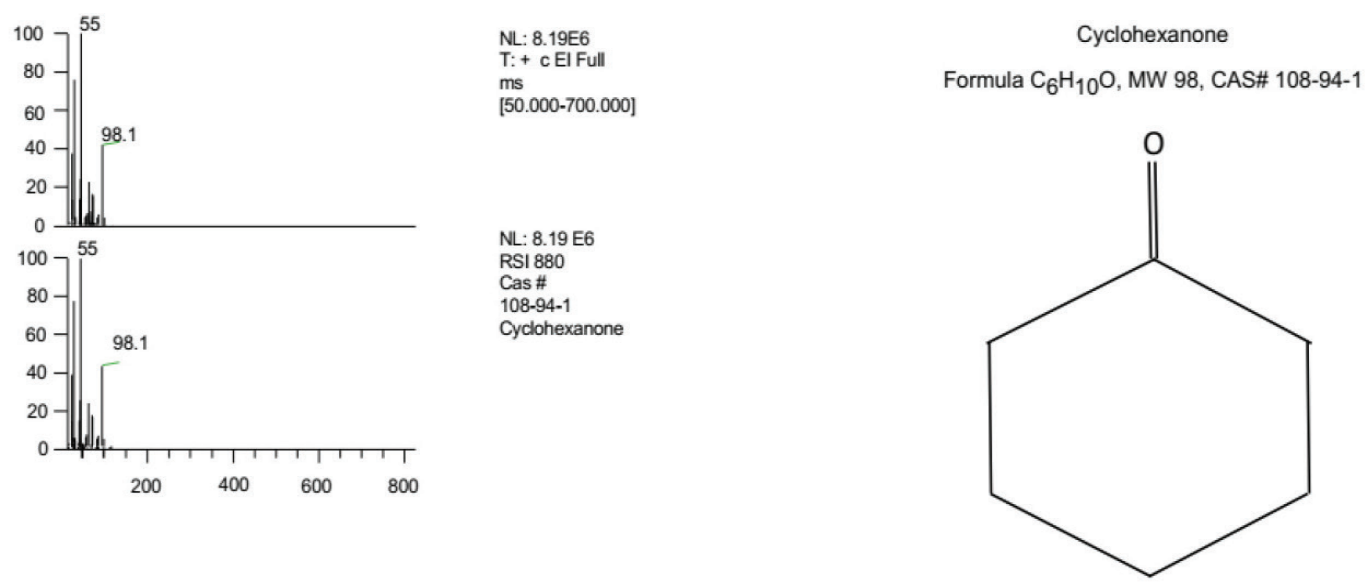

\begin{tabular}{|c|c|c|c|c|c|c|}
\hline RT & Compound Name & Area & Area $\%$ & $\begin{array}{r}\text { Molecular } \\
\text { Formula }\end{array}$ & Molecular Weight & RSI \\
\hline 5.40 & Cyclohexanone & 32669436386.65 & 40.54 & $\mathrm{C}_{6} \mathrm{H}_{10} \mathrm{O}$ & 98 & 880 \\
\hline
\end{tabular}

Fig. S14 - MS of products obtained by cyclohexanol conversion 


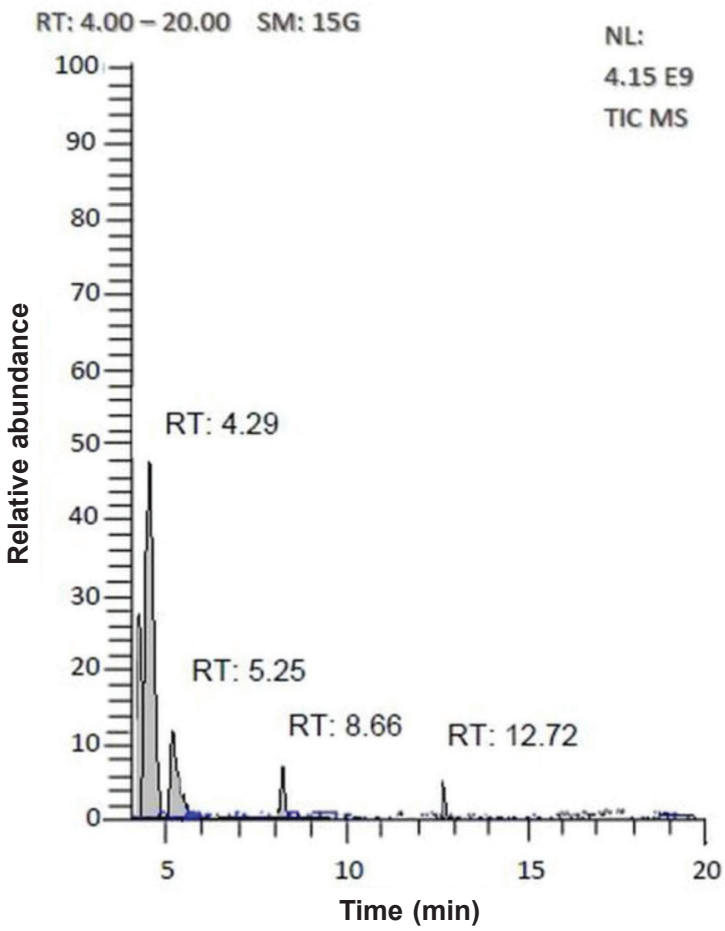

Fig. S $15-$ GC of products obtained by cyclopentanol conversion
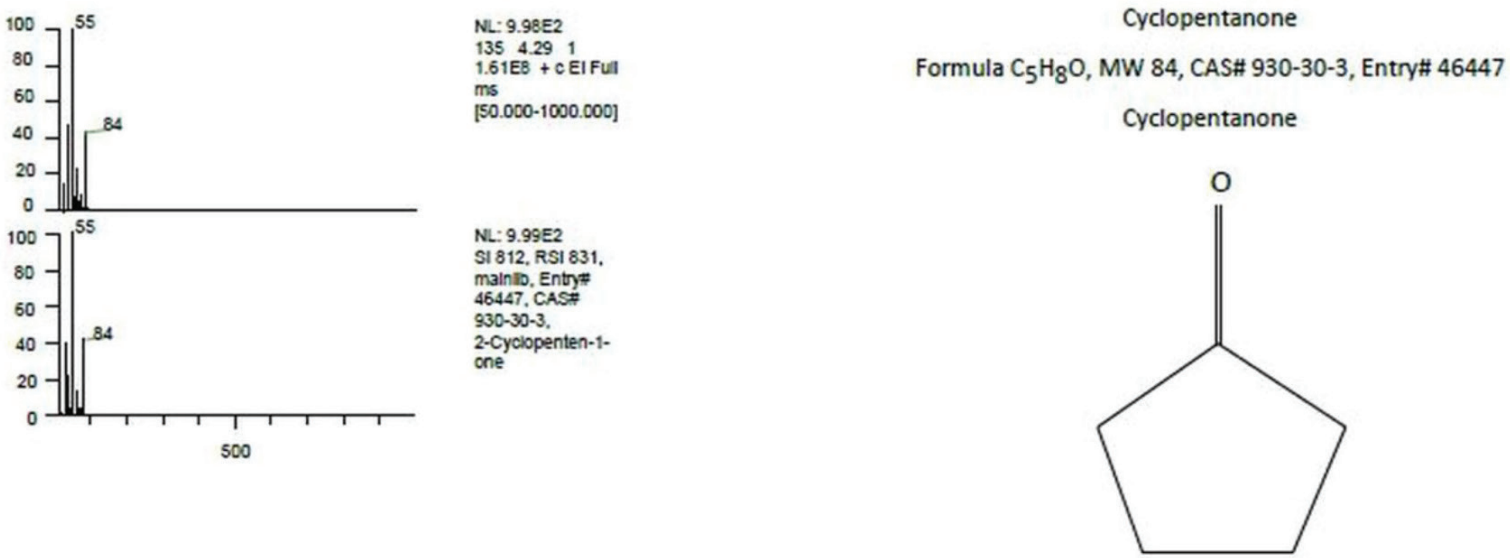

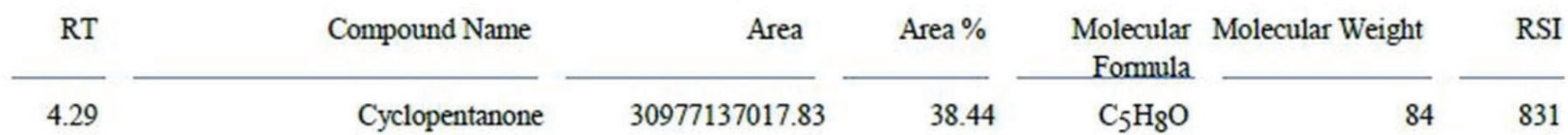

Fig. S $16-$ MS of products obtained by cyclopentanol conversion 


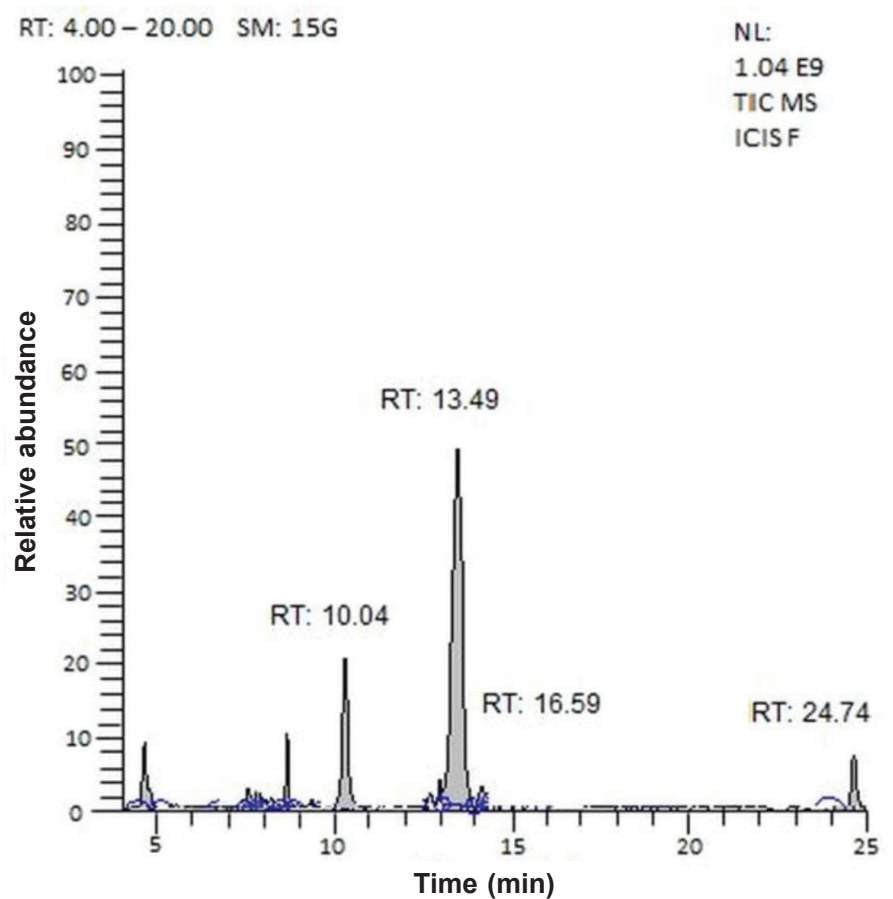

Fig. S17 - GC of products obtained by tetralin conversion in the $2^{\text {nd }}$ catalytic run
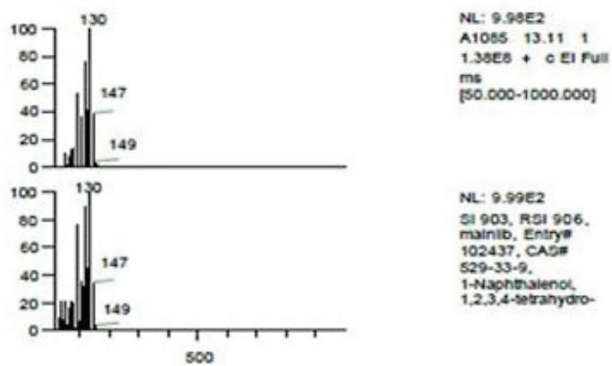

ms

NL: 9.5962

S1903, Ras 906.

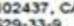

1, -Naphenaienol

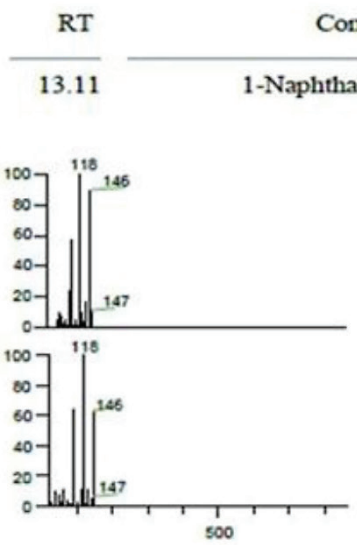

Compound Name
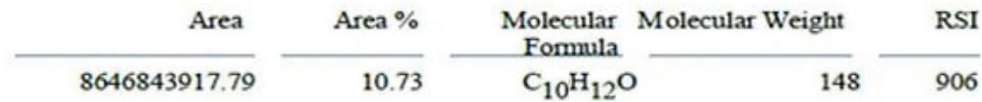

tetrahydro-

1(2H)-Naphthalenone 3,4-dihydro

NL: 9. SOE2

A1130 13.491

ms $000-1000$ 000]

Formula $\mathrm{C}_{10} \mathrm{H}_{10} \mathrm{O}, \mathrm{MW}$ 146, CASH 520-34-0, Entry 87580

Formula $\mathrm{C}_{10} \mathrm{H}_{12} \mathrm{O}$. MW 148, CASen 520-33-9, Entrym 102437
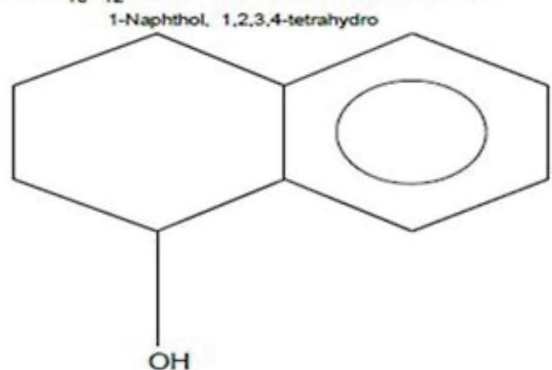

$\mathrm{OH}$

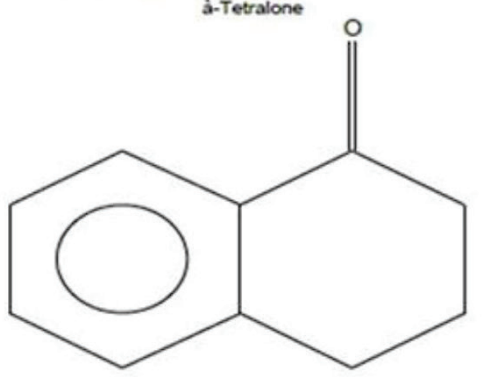

\begin{tabular}{|c|c|c|c|c|c|}
\hline RT & Compound Name & Area & Area \% & $\begin{array}{r}\text { Molecular } \\
\text { Formula } \\
\end{array}$ & Molecular Weight \\
\hline 13.49 & 1(2H)-Naphthalenone, & 25457017648.01 & 31.59 & $\mathrm{C}_{10} \mathrm{H}_{10} \mathrm{O}$ & 146 \\
\hline
\end{tabular}

Fig. S $18-M S$ of products obtained by tetralin conversion in the $2^{\text {nd }}$ catalytic run 


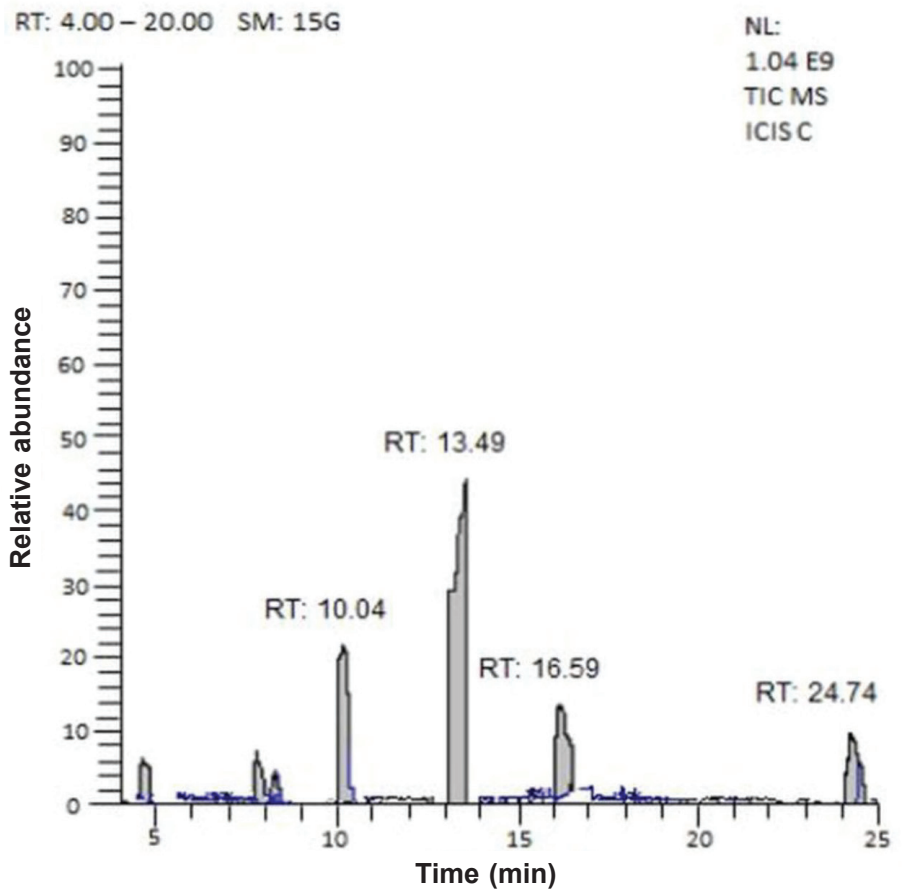

Fig. S19-GC of products obtained by tetralin conversion in the $3^{\text {rd }}$ catalytic run

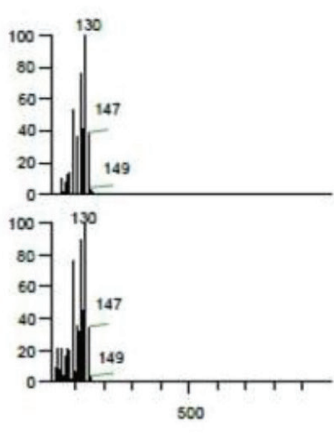

NL: $9.98 E 2$

A1085 13.111

$1.38 E 8+$ CEl Fu

m5

NL: $9.99 E 2$

SI 903, RS1 906

mainito, Entrye

$529-33-9$.

$1-$ Naphtialenol

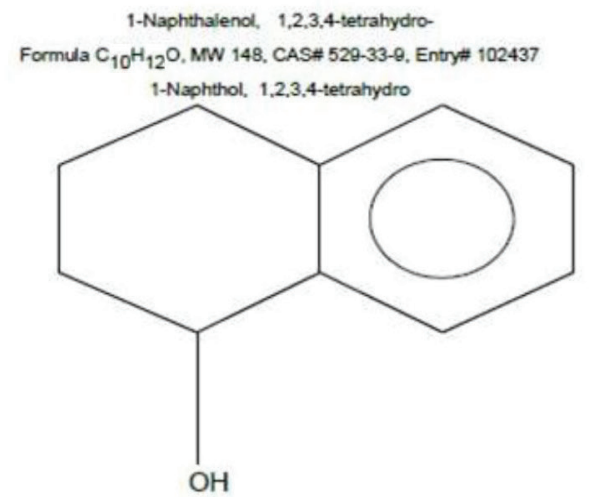

\begin{tabular}{|c|c|c|c|c|c|}
\hline RT & Compound Name & Area & Area $\%$ & $\begin{array}{l}\text { Molecular } \\
\text { Formula }\end{array}$ & Molecular Weight \\
\hline 13.11 & $\begin{array}{r}\text { 1-Naphthalenol, } 1,2,3,4- \\
\text { tetrahydro- }\end{array}$ & 8945010949.46 & 11.10 & $\mathrm{C}_{10} \mathrm{H}_{12} \mathrm{O}$ & 148 \\
\hline
\end{tabular}

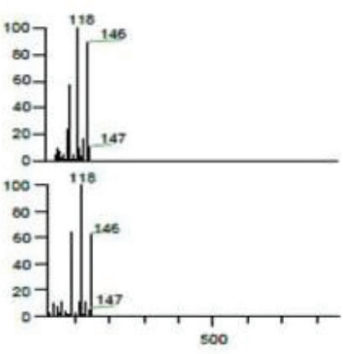

NL: 9.9062 $27350+$ cei ruil

1(2H)-Naphthalenone 3.4-dihydro-

ms $000-10000001$

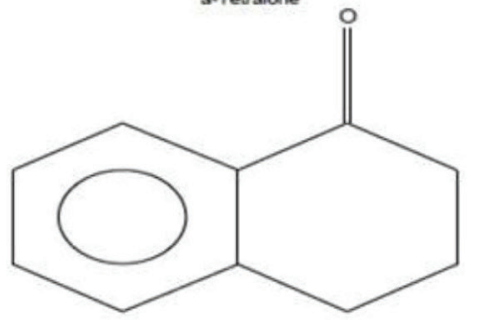

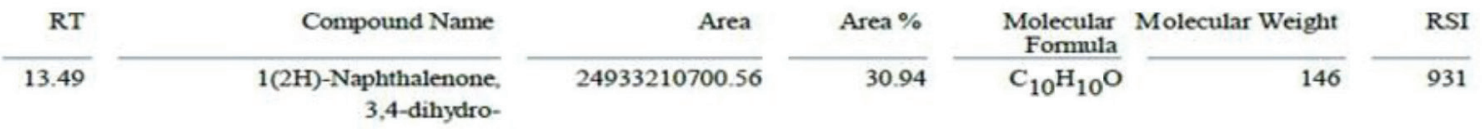

Fig. S2 $0-M S$ of products obtained by tetralin conversion in the $3^{\text {rd }}$ catalytic run 


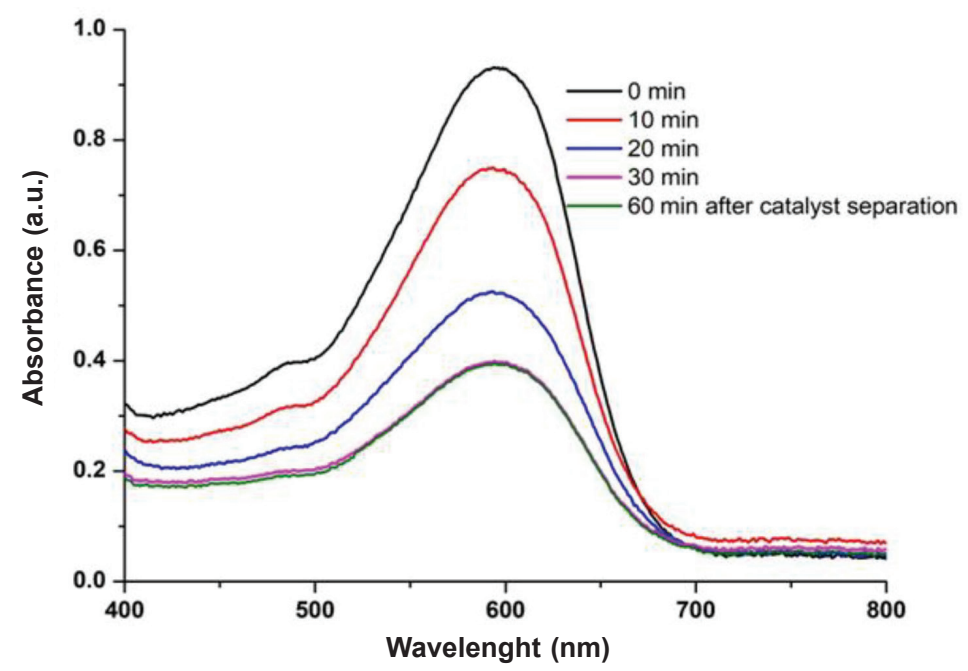

Fig. S2 1 - Time-dependent UV-Vis spectrum of RB5 aqueous solution in presence of catalyst $\left(0.8 \mathrm{~g} \mathrm{~L}^{-1}\right), \mathrm{H}_{2} \mathrm{O}_{2}(17.6 \mathrm{mM})$, and temperature $\left(35 \pm 1{ }^{\circ} \mathrm{C}\right)$ to observe leaching of metal

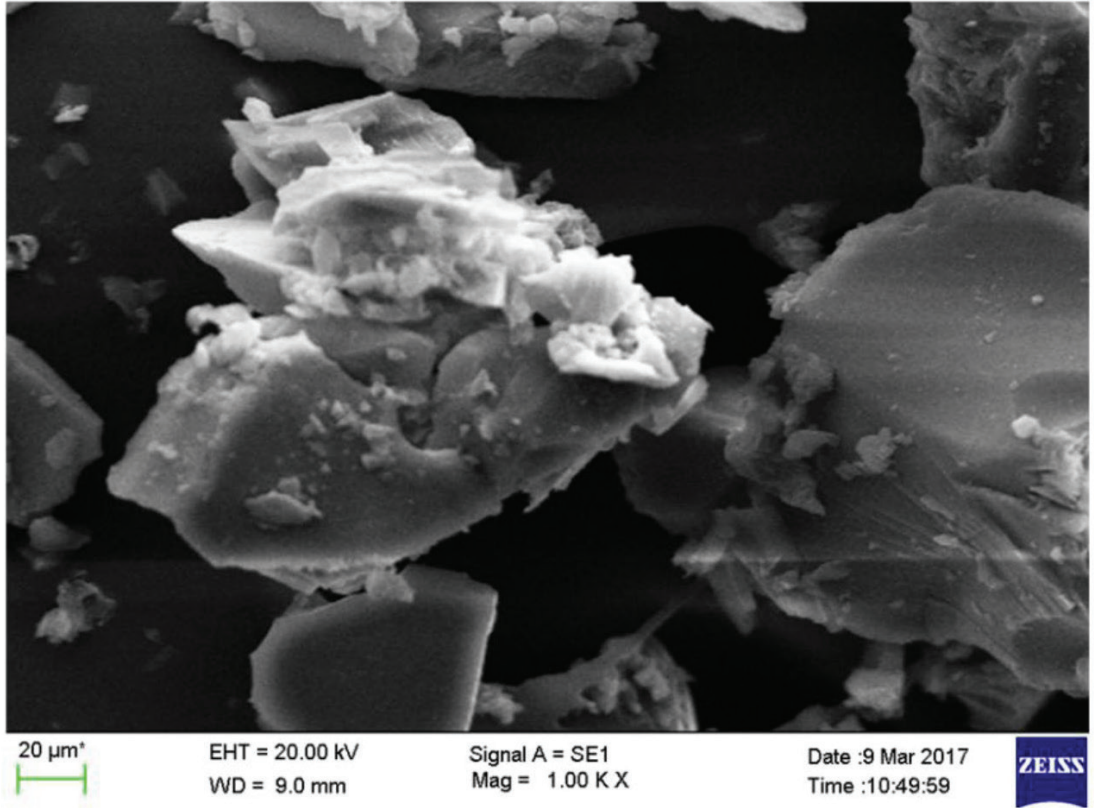

Fig. S22 - SEM image of reused catalyst after first run

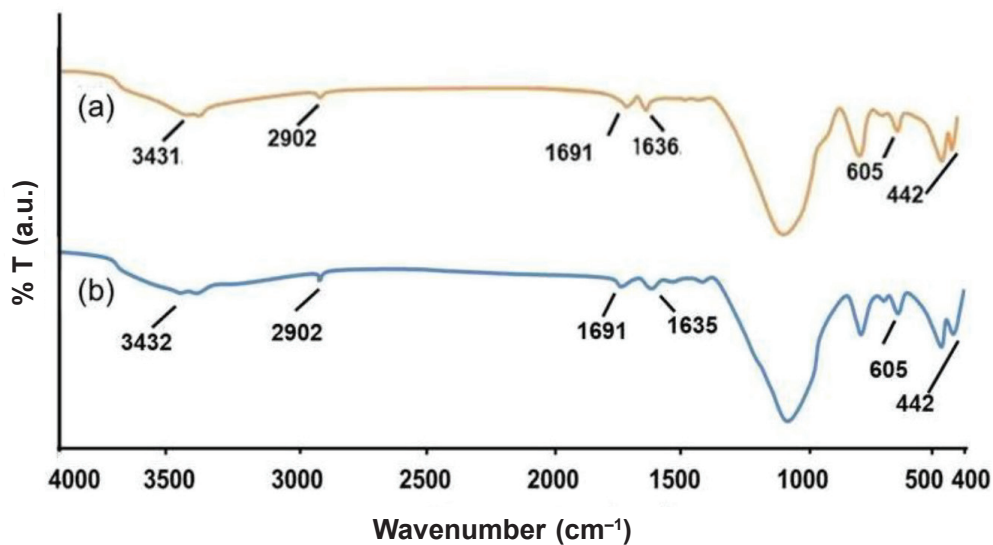

Fig. S23 - FTIR of (a) fresh, and (b) reused catalyst after first catalytic run 


\section{References}

1. Pires de Souza, M. E. P., Ariza, E., Ballester, M., Yoshida, I. V. P., Rocha, L. A., Freire, C. M. A., Characterization of organic-inorganic hybrid coatings for corrosion protection of galvanized steel and electroplated ZnFe steel, Materials Research 9 (2006) 59.

2. Ma, H., Gao, R., Yan, D., Zhao, J., Wei, M., Organic-inorganic hybrid fluorescent ultrathin films and their sensor application for nitroaromatic explosives, J. Mater. Chem. C. 1 (2013) 4128.

3. Noh, J. H., Im, S. H., Heo, J. H., Mandal, T. N., Seok, S., Chemical management for colorful, efficient, and stable inorganic-organic hybrid nanostructured solar cells, Nano Lett. 13 (2013) 1764.

4. Arun, S., Narvi, S. S., Immobilization of copper complex by phosphotungstate, their characterization and application in catalysis, J. Pharm. Appl. Chem. 3 (2017) 27.

5. Junior, J. A. O., Abuçafy, M. P., Manaia, E. B., Lallo da Silva, B., Chiari-Andréo, B. G., Chiavacci, L. A., Drug delivery systems obtained from silica based organic-inorganic hybrids, J. Appl. Polym. Sci. 8 (2016) 91.

6. Urus, S., Purtas, S., Ceyhan, G., Tumer, F., Solid phase extraction of $\mathrm{Pb}(\mathrm{II}), \mathrm{Cu}(\mathrm{II}), \mathrm{Cd}(\mathrm{II})$ and $\mathrm{Cr}(\mathrm{III})$ with syringe technique using novel silica-supported bis(diazoimine) ligands, Chem. Eng. J. 220 (2013) 420.

7. Antony, R., Manickam, S. T. D., Karuppasamy, K., Kollu, P., Chandrasekar, P. V., Balakumar, S., Organic-inorganic hybrid catalysts containing new Schiff base for environment friendly cyclohexane oxidation, RSC Adv. 4 (2014) 42816.

8. Xu, L., Zhou, W., Zhang, L., Li, B., Zang, H., Wang, Y., Li, $Y$., Organic-inorganic hybrid assemblies based on Ti-substituted polyoxometalates for photocatalytic dye degradation, Cryst. Eng. Comm. 17 (2015) 3708.

9. Dui, X., Yang, W., Wu, X., Kuang, X., Liao, J., Yu, R., Lu, $C$., Two novel POM-based inorganic-organic hybrid compounds: Synthesis, structures, magnetic properties, photodegradation and selective absorption of organic dyes, Dalton Trans. 44 (2015) 9496.

10. Volikov, A. B., Ponomarenko, S. A., Konstantinov, A. I., Hatfield, K., Perminova, I. $V$., Nature-like solution for removal of direct brown 1 azo dye from aqueous phase using humics-modified silica gel, Chemosphere 145 (2016) 83.

11. Vinoda, B. M., Vinuth, M., Bodke, Y. D., Manjanna, J., Photocatalytic degradation of toxic methyl red dye using silica nanoparticles synthesized from rice husk ash, J. Environ. Anal. Toxicol. 5 (2015) 336.

12. Abedi, M. H., Ahmadmoazzam, M., Jaafarzadeh, N., Removal of cationic tolonium chloride dye using $\mathrm{Fe}_{3} \mathrm{O}_{4}$ nanoparticles modified with sodium dodecyl sulfate, Chem. Biochem. Eng. Q. 32 (2018) 205.

13. Puasa, S. W., Ruzitah, M. S., Sharifah, A. S. A. K., Competitive removal of Reactive Black 5/Reactive Orange 16 from aqueous solution via micellar-enhanced ultrafiltration, Int. J. Chem. Eng. Appl. 3 (2012) 354.

14. Zhu, X., Zheng, Y., Chen, Z., Chen, Q., Gao, B., Yu, S., Removal of reactive dye from textile effluent through submerged filtration using hollow fiber composite nanofiltration membrane, Desalin. Water. Treat. 51 (2013) 6101.

15. Morsi, M. S., Al-Sarawy, A. A., Shehab El-Dein, W. A., Electrochemical degradation of some organic dyes by electrochemical oxidation on a $\mathrm{Pb} / \mathrm{PbO}_{2}$ electrode, Desalin. Water. Treat. 26 (2011) 301.
16. Lau, Y. Y., Wong, Y. S., Teng, T. T., Morad, N., Rafatullaha, M., Ong, S. A., Degradation of cationic and anionic dyes in coagulation-flocculation process using bi-functionalized silica hybrid with aluminum-ferric as auxiliary agent, RSC Adv. 5 (2015) 34206.

17. Saharan, V. K., Pandit, A. B., Kumar, P. S. S., Anandan, S., Hydrodynamic cavitation as an advanced oxidation technique for the degradation of acid red 88 dye, Ind. Eng. Chem. Res. 51 (2012) 1981.

18. Jain, A., Lodha, S., Punjabi, P. B., Sharma, V. K., Ameta, S. $C$., A study of catalytic behaviour of aromatic additives on the photo-Fenton degradation of phenol red, J. Chem. Sci. 121 (2009) 1027.

19. Wang, J. L., Xu, L. J., Advanced oxidation processes for wastewater treatment: Formation of hydroxyl radical and application, Crit. Rev. Environ. Sci. Technol. 42 (2012) 251.

20. Andreozzi, R., Caprio, V., Insola, A., Marotta, R., Advanced oxidation processes (AOP) for water purification and recovery, Catal. Today 53 (1999) 51.

21. Koo, D. H., Kim, M., Chang, S., $\mathrm{WO}_{3}$ nanoparticles on MCM-48 as a highly selective and versatile heterogeneous catalyst for the oxidation of olefins, sulfides, and cyclic ketones, Org. Lett. 7 (2005) 5015.

22. Arun, S., Narvi, S. S., Pandey, N. D., Pandey, D., Solvothermal synthesis of recyclable heterogeneous catalysts by transition metal complex anchored on polyoxometalate keggin unit, Int. J. Sci. Res. Eng. Dev. 1 (2016) 856.

23. Wang, H., Hu, R., Yang, Y., Gao, M., Wang, Y., Direct catalytic synthesis of $\varepsilon$-caprolactam from cyclohexanol using $\left[\mathrm{n}-\mathrm{C}_{16} \mathrm{H}_{33} \mathrm{~N}\left(\mathrm{CH}_{3}\right)_{3}\right] \mathrm{H}_{2} \mathrm{PW}_{12} \mathrm{O}_{40}$ as a catalyst, Catal. Commun. 70 (2015) 6 .

24. Samir, E. M., The uses of cyclopentanone for the synthesis of biologically active pyran, pyridine and thiophene derivatives, OALib Journal 3 (2016) 1.

25. Covarrubias, Z. A., Cantu, F., Maldonado, L. A., A total synthesis of the racemic sesquiterpene parvifoline, J. Org. Chem. 63 (1998) 2918.

26. Naz, A., Arun, S., Narvi, S. S., Alam, M. S., Singh, A., Bhartiya, P., Dutta, P. K., Cu(II)-carboxymethyl chitosan-silane schiff base complex grafted on nano silica: Structural evolution, antibacterial performance and dye degradation ability, Int. J. Biol. Macromol. 110 (2018) 215.

27. Antony, R., Manickam, S. T. D., Kollu, P., Chandrasekar, P. V., Karuppasamya, K., Balakumara, S., Highly dispersed $\mathrm{Cu}(\mathrm{II}), \mathrm{Co}(\mathrm{II})$ and $\mathrm{Ni}(\mathrm{II})$ catalysts covalently immobilized on imine-modified silica for cyclohexane oxidation with hydrogen peroxide, RSC Adv. 4 (2014) 24820.

28. Radi, S., Tighadouini, S., Bacquet, M., Degoutin, S., Cazier, F., Zaghrioui, M., Mabkhot, Y. N., Organically modified silica with pyrazole-3-carbaldehyde as a new sorbent for solid-liquid extraction of heavy metals, Molecules 19 (2014) 247.

29. Arun, T. R., Raman, N., Antimicrobial efficacy of phenanthrenequinone based Schiff base complexes incorporating methionine amino acid: Structural elucidation and in vitro bio assay, Spectrochim. Acta A Mol. Biomol. Spectrosc. 127 (2014) 292.

30. Soylu, M. S., Yesilel, O. Z., Karabulut, B., Büyükgüngör, O., Syntheses, spectral, thermal and structural characterization of dinuclear and polynuclear copper(II) orotate complexes, $\left[\mathrm{Cu}_{2}(\mathrm{HOr})_{2}\left(\mathrm{H}_{2} \mathrm{O}\right)_{4}\right]$ and $\left[\mathrm{Cu}(\mathrm{l}-\mathrm{HOr})(\mathrm{ba})_{2}\right]_{\mathrm{n}}$, Polyhedron 28 (2009) 2487.

31. Inba, P. J. K., Annaraj, B., Thalamuthu, S., Neelakantan, M. A., $\mathrm{Cu}(\mathrm{II}), \mathrm{Ni}(\mathrm{II})$, and $\mathrm{Zn}(\mathrm{II})$ Complexes of salan-type ligand containing ester groups: Synthesis, characterization, 
electrochemical properties, and in vitro biological activities, Bioinorg. Chem. Appl. 2013 (2013) 1.

32. Radi, S., Tighadouini, S., Bacquet, M., Degoutin, S., Revel, B., Zaghrioui, M., Quantitative removal of $\mathrm{Zn}$ (II) from aqueous solution and natural water using new silica-immobilized ketoenol-pyridine receptor, J. Environ. Chem. Eng. 3 (2015) 1769.

33. Singh, G., Rani, S., Arora, A., Sanchita, Duggal, H., Mehta, $D$., Organic-inorganic nano-hybrid decorated by copper (II) incarceration: A versatile catalytic assembly for the swift reduction of aromatic nitro and dye compounds, Mol. Catal. 431 (2017) 15.

34. Ahmed, A., Lal, R. A., Synthesis, characterization and electrochemical studies of copper(II) complexes derived from succinoyl- and adipoyldihydrazones, Arabian J. Chem. 10 (2017) S901.

35. Kivelson D., Neiman R., ESR studies on the bonding in copper complexes, J. Chem. Phys. 35 (1961) 149.

36. Verma, P., Shah, V., Baldrian, P., Gabriel, J., Stopka, P., Trnka, T., Nerud, F., Decolorization of synthetic dyes using a copper complex with glucaric acid, Chemosphere $\mathbf{5 4}$ (2004) 291.

37. Shah, V., Verma, P., Stopka, P., Gabriel, J., Baldrian, P., Nerud, F., Decolorization of dyes with copper(II)/organic acid/hydrogen peroxide systems, Appl Catal B: Environmental 46 (2003) 287.

38. Perez-Benito, J. F., Reaction pathways in the decomposition of hydrogen peroxide catalyzed by copper(II), J. Inorg. Biochem. 98 (2004) 430

39. Baldrian, P., Merhautova, V., Gabriel, J., Nerud, F., Stopka, P., Hruby, M., Benes, M. J., Decolorization of synthetic dyes by hydrogen peroxide with heterogeneous catalysis by mixed iron oxides, Applied Catalysis B: Environmental 66 (2006) 258 .

40. Lin, T. Y., Wu, C. H., Activation of hydrogen peroxide in copper(II)/amino acid $/ \mathrm{H}_{2} \mathrm{O}_{2}$ systems: Effects of $\mathrm{pH}$ and copper speciation, J. Catal. 232 (2005) 117.
41. Lucas, M. S., Peres, J. A., Decolorization of the azo dye Reactive Black 5 by Fenton and photo-Fenton oxidation, Dyes Pigm. 71 (2006) 236.

42. Nasuha, N., Ismail, S., Hameed, B. H., Activated electric arc furnace slag as an efficient and reusable heterogeneous Fenton-like catalyst for the degradation of Reactive Black 5, J. Taiwan Inst. Chem. Eng. 67 (2016) 235.

43. Ramirez, J. H., Maldonado-Hódar, F. J., Pérez-Cadenas, A. F., Moreno-Castilla, C., Costa, C. A., Madeira, L. M., Azodye Orange II degradation by heterogeneous Fenton-like reaction using carbon-Fe catalysts, Applied Catalysis B: Environmental 75 (2007) 312.

44. Soon, A. N., Hameed, B. H., Degradation of Acid Blue 29 in visible light radiation using iron modified mesoporous silica as heterogeneous Photo-Fenton catalyst, Applied Catalysis A: General 450 (2013) 96.

45. Wang, Y., Wang, J., Zou, H., Xie, Y., Heterogeneous activation of hydrogen peroxide using $\gamma-\mathrm{Al}_{2} \mathrm{O}_{3}$ supported bimetallic $\mathrm{Fe}, \mathrm{Mn}$ for the degradation of reactive black 5, RSC Adv. 6 (2016) 15394.

46. Modi, C. K., Trivedi, P. M., Zeolite-Y entrapped Ru(III) and $\mathrm{Fe}(\mathrm{III})$ complexes as heterogeneous catalysts for catalytic oxidation of cyclohexane reaction, Arabian J. Chem. 10 (2017) S1452

47. Arun, S., Singh, V. K., Naz, A., Narvi, S. S., Dutta, P. K., A comparative catalytic study using different metal ions by incorporating functionalized metallosalen into the lacunary position of Keggin polyoxometalate, J. Indian Chem. Soc. 98 (2021) 100118.

48. Lau, Y. -Y., Wong, Y. -S., Ang, T. -Z., Ong, S. -A., Lutpi, N. A., Ho, L. -N., Degradation reaction of Diazo reactive black 5 dye with copper (II) sulfate catalyst in thermolysis treatment, Environ. Sci. Pollut. Res. 25 (2018) 7067.

49. Salem, I. A., Shaltout, M. H., Zaki, A. B., Homogeneous and heterogeneous catalytic oxidation of some azo dyes using copper(II) ions, Spectrochim. Acta, Part A. 227 (2020) 117618. 